NBER WORKING PAPER SERIES

\title{
IS CREDIT EVENT RISK PRICED? MODELING CONTAGION VIA THE UPDATING OF BELIEFS.
}

Pierre Collin-Dufresne

Robert S. Goldstein

Jean Helwege

Working Paper 15733

http://www.nber.org/papers/w15733

\author{
NATIONAL BUREAU OF ECONOMIC RESEARCH \\ 1050 Massachusetts Avenue \\ Cambridge, MA 02138 \\ February 2010
}

The views expressed herein are those of the authors and do not necessarily reflect the views of the National Bureau of Economic Research.

NBER working papers are circulated for discussion and comment purposes. They have not been peerreviewed or been subject to the review by the NBER Board of Directors that accompanies official NBER publications.

(C) 2010 by Pierre Collin-Dufresne, Robert S. Goldstein, and Jean Helwege. All rights reserved. Short sections of text, not to exceed two paragraphs, may be quoted without explicit permission provided that full credit, including $(\mathcal{C}$ notice, is given to the source. 
Is Credit Event Risk Priced? Modeling Contagion via the Updating of Beliefs.

Pierre Collin-Dufresne, Robert S. Goldstein, and Jean Helwege

NBER Working Paper No. 15733

February 2010

JEL No. G12,G13

\begin{abstract}
Empirical tests of reduced form models of default attribute a large fraction of observed credit spreads to compensation for jump-to-default risk. However, these models preclude a "contagion-risk" channel, where the aggregate corporate bond index reacts adversely to a credit event. In this paper, we propose a tractable model for pricing corporate bonds subject to contagion-risk. We show that when investors have fragile beliefs (Hansen and Sargent (2009)), contagion premia may be sizable even if P-measure contagion across defaults is small. We find empirical support for contagion in bond returns in response to large credit events. Model calibrations suggest that while contagion risk premia may be sizable, jump-to-default risk premia have an upper bound of a few basis points.
\end{abstract}

Pierre Collin-Dufresne

Graduate School of Business

Columbia University

Uris Hall 404

3022 Braodway

New York, NY 10027

and NBER

pc2415@columbia.edu

Robert S. Goldstein

University of Minnesota

Finance Department

3-125 Carlson School of Management

321 19th Avenue South

Minneapolis, MN 55455

and NBER

golds144@umn.edu
Jean Helwege

318 Business Building

Smeal College of Business

Penn State University

University Park, PA 16802

Juh20@psu.edu 


\section{Introduction}

Most empirical studies of structural models of default have found that only a small fraction of observed credit spreads for investment grade debt can be explained in terms of compensation for credit risk. (See Jones, Mason and Rosenfeld (1984), Huang and Huang (2003), Eom, Helwege and Huang (2004)). The problem is especially severe for investment grade bonds with short maturities. Indeed, if firm value dynamics are specified as a diffusion process, then structural models predict a negligible default probability for short maturity debt.

In contrast to structural models, reduced-form (or hazard rate) models of default abstract from firm value dynamics and directly model default as a jump event. Reduced-form models posit a process for the risk-neutral default intensity $\lambda^{Q}(t)$, and then value risky claims by discounting at a default-adjusted rate under the risk-neutral measure. Under certain modeling assumptions, the price of a corporate bond obtains the same analytic form as that found for a risk-free bond (Lando (1998), Duffie and Singleton (1999)). Indeed, it is this tractability that explains the popularity of reduced-form models. However, the strength of the reduced-form framework (i.e., its tractability and flexibility) is also its weakness: Because they provide little in terms of economic theory for default dynamics, reduced form models offer very limited "outof-sample" predictions about credit spreads. As such, they are as good (or as bad) as their underlying assumptions regarding default intensity and recovery rate dynamics.

Most sources of risk found in structural models have an analogue in reduced form models. ${ }^{1}$ For example, just as common movements in firm values lead to risk premia for corporate bonds in a structural framework, common movements in intensities justify these same risk premia in the reduced form framework, since such risks are not mitigated by holding well-diversified portfolios. However, reduced-form models have an additional channel for capturing compensation for risk not found in (diffusion-based) structural models, namely, the (unpredictable) jump-to-default (JTD) event itself. When this risk is priced, the risk-neutral intensity $\lambda^{Q}(t)$ can be higher than the actual default intensity $\lambda^{P}(t)$. In fact, empirical studies of reducedform model ascribe a large part of the credit spread to this JTD risk-channel. For example, Driessen (2005) estimates the jump-risk premium for 10-year BBB bonds in his benchmark case to be $31 \mathrm{bp}$, and the ratio of risk-neutral intensity to actual default intensity $\left(\frac{\lambda^{Q}(t)}{\lambda^{P}(t)}\right)$ to be 2.3. Similar results are reported by Berndt et al (2005), who instead focus on credit default swaps. We emphasize that these papers do not estimate the jump-risk premia directly. That is, they do not investigate how their proxy for the pricing kernel covaries with bond

\footnotetext{
${ }^{1}$ Indeed, Duffie and Lando (2001) demonstrate that when one adds uncertainty to the true firm value in a structural model, the model effectively reduces to a reduced-form model.
} 
returns during credit events. Instead, researchers typically estimate the "traditional" channels directly, and then simply attribute the residual to jump-to-default risk. Thus, the accuracy of the jump-to-default risk premium estimate depends crucially on the model being well-specified.

However, we argue in this paper that large JTD risk-premia lead to a bit of a conundrum. First, for JTD risk to be priced, it must be that JTD is not conditionally diversifiable. ${ }^{2}$ Second, if JTD is indeed not conditionally diversifiable, then this implies that there should be another source of credit risk-premium, namely, a contagion risk premium, which is due to a marketwide adverse reaction to a given firm's default. An implication of this argument is that models which ignore contagion risk may not be well-specified, in turn leading to a JTD risk premium that is biased upward.

Interestingly, when we consider a framework where JTD risk is priced because of its covariance with the returns of the corporate bond index, we find that the JTD premium has an upper bound of only a few basis points. The intuition for this result is straightforward: if there are $N=1000$ firms that compose the aggregate corporate bond market, then it is 1000-times more likely for a given corporate bond to share in the contagion event than it is for that bond to jump to default. A standard no arbitrage argument then implies that the market portfolio loss would have to be approximately 1000-times smaller than the loss on the defaulting bond for the contagion premium not to dwarf JTD premium. However, such a small impact on the market portfolio would imply that the jump-to-default event would be almost idiosyncratic, and therefore would not command a significant risk premium. Below, we show that the JTD premium is approximately linear, and the contagion premium quadratic, in the coefficient controlling the level of contagion. We find that as we increase the value of this coefficient, the contagion risk premium 'explains' virtually all of the observed credit spread before the JTD premium can reach a size larger than a few basis points.

This implication is problematic, however, since only JTD risk, and not contagion-risk, can explain short-maturity spreads. This then strongly suggests that short-maturity spreads are not due to jump-to-default risk, but rather to non-credit factors, such as liquidity-risk. Such conclusions have important implications for optimal portfolio decisions, risk-management, and welfare concerns.

We believe that contagion risk has been mostly ignored in the previous literature not because it was deemed as unimportant, but rather due to technical reasons. Indeed, tractable solutions for defaultable bonds had only been identified for those models that fell within the "no jump at default" frameworks of Duffie, Schroeder and Skiadas (1996) and Duffie and Singleton

\footnotetext{
${ }^{2}$ This point has been made elegantly by Jarrow, Lando, Yu (2001).
} 
(1999), and the "Cox-process" framework described in Lando (1998). The tractability of these frameworks stemmed directly from their assumption that no contagion risk was present.

One contribution of this paper is to identify a simple and economically intuitive framework that tractably captures contagion risk. We propose a reduced-form framework that provides analytic solutions for risky bond prices even though the model falls outside of the "no jump at default" framework. In our model, an unexpected default of an individual firm leads to a market-wide increase in credit spreads. Thus, jump-to-default risk is not conditionally diversifiable, and hence commands a risk premium. While this framework is consistent with a counterparty-risk interpretation, it is most naturally interpreted as an updating of beliefs about the economic environment due to an unexpected default event. Recent examples of a credit event affecting beliefs about defaults of other firms include the Enron default, where beliefs about accounting quality across many firms were impacted, and the leveraged buyout of RJR, which impacted the beliefs about how large a firm could be and still have outstanding corporate bonds subject to the risk of an LBO. ${ }^{3}$

In our calibration below, we consider both jumps to default and the much more common occurrence of a large jump in credit spreads (i.e., jump in risk-neutral intensity), both of which can lead to updating and therefore contagion. In both cases, we conclude that the jump risk premium is necessarily small.

Ultimately, it is an empirical question whether credit events are associated with a contagious response. Therefore, we also perform an 'event study' on a large sample of corporate bond returns. We identify months that include a surprise credit event (defined as a large jump in bond prices, identified first by isolating large credit spread jumps, and then confirmed by actual news event) of an investment grade firm, and compare aggregated bond returns in those months to non-event months. We find that credit events lead to both market-wide increases in credit spreads and to significant spill-over returns in Treasury bonds, consistent with a 'flight to quality' interpretation. The contagion effects are more pronounced for larger firms than for smaller firms, and do not appear to be explained by a host of control variables.

Our paper builds on and combines two important strands of literature: event risk and Bayesian updating of beliefs. Conditions for which jump-to-default is not priced have been investigated by Jarrow, Lando and Yu (2005). They demonstrate that under some standard APT-like assumptions ${ }^{4}$ that jump-to-default risk will not be priced if the default process is assumed to follow a so-called "doubly stochastic" (or Cox) process. However, recent empiri-

\footnotetext{
${ }^{3}$ See Crabbe (1994), Yu (2005)

${ }^{4}$ These assumptions include: i) each firm constitutes a small fraction of the economy, ii) a finite fraction of firms do not default simultaneously, and iii) marginal investors can diversify their bond portfolio holdings.
} 
cal findings question this doubly-stochastic assumption. For example, Das et al. (2006, 2007) report that the observed clustering of defaults in actual data are inconsistent with this assumption. Duffie et al (2009) use a fragility-based model similar to ours to identify a hidden state variable consistent with a contagion-like response. Note that the focus of these papers is on estimating the empirical default probability, whereas our focus is on pricing. Jorion and Zhang (2007) find contagious effects at the industry level. ${ }^{5}$

Other papers investigating event risk include Jarrow and Yu (2001), who also provide a model where the default of one firm affects the intensity of another. However, their model remains tractable only for a "small" number $N$ of firms exposed to contagion-risk (e.g., JY investigate only $N=2$ ). In contrast, our model remains tractable regardless of the number of firms that share in the contagious response. Such a framework is necessary for our purposes since we want to investigate how large the jump-to-default risk premium can be when the number of firms is large. ${ }^{6}$

Our approach shares many common features with those in the learning and contagion literature (Detemple (1986), Feldman (1989), David (1997), Veronesi (2000)). As in these papers, the representative agent in our economy learns about a hidden state from observing aggregate consumption. However, in addition in our model the agent learns from individual firms' defaults history. ${ }^{7}$ Further, we identify a dynamically-consistent model of a representative agent that has fragile beliefs (Hansen and Sargent (2009), Hansen (2007)). Dynamic consistency allows us to price securities with long-dated cash flows in a tractable manner. This framework naturally generates a flight-to-quality (i.e., a drop in risk free rates) caused by an unexpected default, consistent with observation.

Our information-based mechanism for contagion is similar to that proposed by King and Wadhwani (1990) and Kodres and Pritsker (2002), who investigate contagion across international financial markets. There is also a large empirical literature that studies contagion in equity markets (e.g., Lang and Stulz (1992)) and in international finance (e.g., Bae, Karolyi and Stulz (2003)). Theocharides (2007) investigates contagion in the corporate bond market and finds empirical support for information-based transmission of crises.

The rest of the paper is as follows. In Section 2, we review the relevant literature regarding

\footnotetext{
${ }^{5}$ Related, also see Jorion and Zhang (2009), Lando and Nielsen (2009).

${ }^{6}$ Collin-Dufresne, Goldstein and Hugonnier (2004) simplify the bond pricing formula of Duffie, Schroeder and Skiadis (1996). Note, however, that the formula itself does not identify a tractable framework for pricing contagion risk. Other models of contagion include Davis and Lo (2001), Schönbucher and Schubert (2001), and Giesecke (2004).

${ }^{7}$ I addition, a minor technical difference between these papers and ours is that they use results on filtering theory for diffusions, whereas in our case information is revealed through jump-diffusion processes.
} 
jump to default risk, and explain why it is difficult to capture contagion risk within a tractable framework. In Section 3, we investigate a simple production economy as in Ahn and Thompson (1988) and demonstrate that jump-to-default premia have an upper bound of a few basis points if returns on the corporate bond index can proxy for the pricing kernel. In Section 4, we propose a model that captures contagion-risk in a tractable framework. In Section 5, we investigate the nature of risk-premia for our contagion-risk in a 'fragile beliefs' framework. In Section 6, we investigate empirically the impact that major credit events has had on the corporate bond index. We conclude in Section 7.

\section{Reduced Form Models: Background}

\subsection{Sources of risk}

In this section, we distinguish between jump-to-default risk and intensity risk in reduced form models of default. In the following section, we investigate situations for which jump-to-default risk will be priced.

\subsubsection{Jump Risk}

Reduced form models of default ${ }^{8}$ assume that default is triggered by the jump of an unpredictable point process $\mathbf{1}_{\{\tau<t\}}$, where $\tilde{\tau}$ is the random default time. The intensities under the historical probability measure $\lambda^{P}$ and risk neutral measure $\lambda^{Q}$ associated with this default event are defined via

$$
\begin{aligned}
& \mathrm{E}_{t}^{P}\left[d \mathbf{1}_{\{\tau \leq t\}}\right]=\lambda_{t}^{P} \mathbf{1}_{\{\tau>t\}} d t \\
& \mathrm{E}_{t}^{Q}\left[d \mathbf{1}_{\{\tau \leq t\}}\right]=\lambda_{t}^{Q} \mathbf{1}_{\{\tau>t\}} d t
\end{aligned}
$$

Intuitively, these equations imply that the probability of a jump to default during the interval $(t, t+\Delta t)$, conditional upon no prior default, is $\lambda_{t} \Delta t$.

Regardless of whether a model is partial equilibrium (where the pricing kernel is specified exogenously) or general equilibrium (where the pricing kernel is derived endogenously from the agent's preferences and the technologies available), if $d \mathbf{1}_{\{\tau \leq t\}}$ is contained in pricing kernel dynamics, then this source of risk is priced, and $\lambda_{t}^{Q}$ will not equal $\lambda_{t}^{P} \cdot{ }^{9}$ As a simple example,

\footnotetext{
${ }^{8}$ See, for example, Jarrow, Lando and Turnbull (1997), Madan and Unal (1998), Duffie and Singleton (1997).

${ }^{9}$ This is the well-known result of the change of measure, i.e., Girsanov's theorem for point processes. If the Radon-Nykodim derivative has a common jump with the point process then its intensity may be modified under the new measure. Examples of this are provided in equations (8) and (23) below.
} 
we specify the pricing kernel to be of the form

$$
\frac{d \Lambda}{\Lambda}=-r d t+\Gamma\left(d \mathbf{1}_{\{\tau \leq t\}}-\lambda_{t}^{P} \mathbf{1}_{\{\tau>t\}} d t\right)
$$

where $r$ is the risk free rate and $\Gamma$ is the size of the jump in the pricing kernel in the event of default (i.e., $d \mathbf{1}_{\{\tau \leq t\}}=1$ ). Consider a risky bond with (ex-dividend) price $P(t)$ that, upon default, becomes worthless upon paying out a terminal dividend equal to the fraction $(1-L)$ of its pre-default market value. Its historical and risk-neutral dynamics are expressed as:

$$
\begin{aligned}
\frac{d P+(1-L) P d \mathbf{1}_{\{\tau \leq t\}}}{P} & =\mu d t-L\left(d \mathbf{1}_{\{\tau \leq t\}}-\lambda_{t}^{P} \mathbf{1}_{\{\tau>t\}} d t\right) \\
& =r d t-L\left(d \mathbf{1}_{\{\tau \leq t\}}-\lambda_{t}^{Q} \mathbf{1}_{\{\tau>t\}} d t\right) .
\end{aligned}
$$

Combined, these equations imply:

$$
(\mu-r)=L\left(\lambda^{Q}-\lambda^{P}\right) \mathbf{1}_{\{\tau>t\}}
$$

Using the definition of a pricing kernel, we find the relation

$$
\begin{aligned}
0 & =\frac{1}{d t} \mathrm{E}^{P}\left[\frac{d P}{P}+\frac{d \Lambda}{\Lambda}+\frac{d P}{P} \frac{d \Lambda}{\Lambda}\right] \\
& =\mu-r-L \Gamma \lambda^{P} \mathbf{1}_{\{\tau>t\}} .
\end{aligned}
$$

Combining this with equation (6), we find

$$
\frac{\lambda^{Q}}{\lambda^{P}}=(1+\Gamma)
$$

This simple example demonstrates two important implications of JTD risk. First, JTD risk of firm- $i$ is priced if and only if the pricing kernel jumps at the time of firm $i$ 's default $(\Gamma \neq 0)$. In that case, the ratio $\frac{\lambda^{Q}}{\lambda^{P}}$ will differ from unity, and the compensation (i.e., expected excess return) for jump-to-default risk is

$$
(\mu-r)=L\left(\lambda^{Q}-\lambda^{P}\right) \mathbf{1}_{\{\tau>t\}}=L \Gamma \lambda^{P} \mathbf{1}_{\{\tau>t\}} .
$$

Hence, JTD can potentially explain high risk-premia on corporate bonds. Second, JTD translates into higher short term credit spreads since, solving equation (5) (for the case of constant drifts and intensities ${ }^{10}$ we see that

$$
P(t, T)=e^{-\left(\mu+\lambda^{P} L\right)(T-t)} \mathbf{1}_{\{\tau>t\}}=e^{-\left(r+\lambda^{Q} L\right)(T-t)} \mathbf{1}_{\{\tau>t\}} .
$$

\footnotetext{
${ }^{10}$ Similar arguments hold in the more general case of non-constant drifts and intensities.
} 
Thus, the instantaneous credit spread is $\lambda^{Q} L$, which exceeds the instantaneous expected loss $\lambda^{P} L$ if JTD is priced (that is, if $\Gamma>0$ ). On the flip side, this example shows that if many firms are to have priced JTD risk, then each individual default must affect the pricing kernel. We emphasize that this JTD channel has no analogue in diffusion based structural models of default. $^{11}$

\subsubsection{Intensity Risk}

In addition to jump-to-default risk, the intensity $\lambda_{t}^{P}$ (and hence, in general, also $\lambda_{t}^{Q}$ ) itself is specified to have stochastic dynamics, capturing the fact that the likelihood of default changes over time. In particular, its dynamics can change randomly due to both Brownian motions $z$ and jumps $q$ :

$$
\begin{aligned}
d \lambda_{t}^{P} & =\mu_{\lambda}^{P} d t+\sigma_{\lambda} d z_{t}^{P}+\widetilde{\Gamma_{\lambda}} d q_{t} \\
& =\mu_{\lambda}^{Q} d t+\sigma_{\lambda} d z_{t}^{Q}+\widetilde{\Gamma_{\lambda}} d q_{t}
\end{aligned}
$$

If changes in $\lambda^{P}$ are correlated with changes in the pricing kernel, then at least one of the sources of risk $d z$ and $d q$ is priced, and the dynamics for $\lambda^{P}$ will differ under the historical and risk-neutral measures.

Equations (1)-(10) demonstrate that reduced-form models encapsulate two different types of risk premia. First, risk premia can be due to sources of risk that drive the dynamics of the intensity $\left(d z^{P}, d q\right)$. These risk sources have an analogue in structural models of default, where $\left(d z^{P}, d q\right)$ would drive the dynamics of distance-to-default. Duffee (1999) and Driessen (2005) provide convincing evidence that such risk premia exist in reduced form models, whereas Elton et al. (2001) and Collin-Dufresne, Goldstein and Martin (2001) provide similar evidence that such risk premia exist in structural models. Second, the jump-to-default random variable $d \mathbf{1}_{\{\tau \leq t\}}$ can command a risk premium itself, in which case $\lambda^{P} \neq \lambda^{Q}$. This source of risk has no analogue in diffusion-based structural models of default, and hence can potentially help explain the empirical failures of structural models. We emphasize that these risk premia are empirically distinguishable, both in time-series and in cross-section. In time series, for example, $d \mathbf{1}_{\{\tau \leq t\}}$ is priced only if there is a market-wide response at the default event. In cross-section, abstracting from taxes and liquidity, only jump-to-default risk can generate credit spreads that are higher than expected loss rates at the very short end of the yield curve.

\footnotetext{
${ }^{11}$ For a structural model with jumps, see Zhou (2001).
} 


\subsection{Conditions for Jump-to-Default Risk to be Priced}

In equation (3), we have simply assumed that jump-to-default risk is priced. One major focus of this paper is to investigate the conditions for which jump-to-default risk is priced for the typical $^{12}$ corporate bond. Recently, there has been considerable research on this topic. For example, by extending the arguments implicit in the APT framework, Jarrow, Lando and Yu (2005) discuss the conditions for which no systematic jump-to-default-risk exists. Essentially, their results show that if the following two conditions are satisfied:

(i) Conditional on the state variables driving intensities, default events are independent.

(ii) A large number of bonds are available for trading,

then jump-risk is conditionally diversifiable, and therefore should not command a risk-premium.

There are at least two scenarios where condition i) would not hold, and thus jump-risk would be priced. First, there can be systemic risk in the sense that several firms can default at the same time (i.e., $\left[d \mathbf{1}_{\left\{\tau_{i} \leq t\right\}} d \mathbf{1}_{\left\{\tau_{j} \leq t\right\}}\right] \neq 0 \forall i, j \in[1, N]$ ). Intuitively, if the number of firms $N$ is large enough that a non-negligible part of the economy defaults at the same date, then such a risk would command a risk-premium. However, there is little empirical support for such a notion. (Of course, there is always the concern of a 'Peso-problem').

Second, there can be contagion-risk in the sense that the default of one firm can trigger an increase in the risk (i.e., an increase in the intensity) of default of other firms. Mathematically, we can write this as $\left[d \mathbf{1}_{\left\{\tau_{i} \leq t\right\}} d \lambda_{j}(t)\right] \neq 0 \forall i, j \in[1, N]$. In this paper, we show how introducing contagion risk allows jump-to-default risk to be priced, and then demonstrate the quantitative restrictions contagion risk imposes on the size of the jump-to-default premia.

Unfortunately, accounting for contagion risk destroys the tractability of the previously proposed models in the literature. Indeed, the empirical literature has focused on those models where the zero-recovery, zero-coupon risky bond price

$$
P^{T}(0)=\mathrm{E}_{0}^{Q}\left[e^{-\int_{0}^{T} d s r(s)} \mathbf{1}_{\{\tau>T\}}\right]
$$

can be re-expressed as

$$
\mathrm{E}_{0}^{Q}\left[e^{-\int_{0}^{T} d t\left(r(t)+\lambda^{Q}(t)\right)}\right] \mathbf{1}_{\{\tau>0\}}
$$

However, as noted by Duffie, Schroeder and Skiadas (DSS, 1996), Duffie and Singleton (1999) and Lando (1998), when there is contagion-risk, then equation (11) is typically not equal to equation (12).

\footnotetext{
${ }^{12}$ We emphasize that this paper focuses on the JTD premia for the typical, or average bond. There is little doubt that a credit event associated with the largest firms in the economy would command significantly larger JTD premia.
} 
An example where the equality between (11) and (12) does not hold is the $(\mathrm{N}=2)$ counterparty-risk model of Jarrow and Yu (JY 2001):

$$
\begin{aligned}
& \lambda_{1}^{Q}(t)=a_{11}+a_{12} \mathbf{1}_{\left\{\tau_{2} \leq t\right\}} \\
& \lambda_{2}^{Q}(t)=a_{21} \mathbf{1}_{\left\{\tau_{1} \leq t\right\}}+a_{22} .
\end{aligned}
$$

Intuitively, this model captures the notion that a default of one firm affects the intensity/probability of future default of another firm. Unfortunately, however, this framework becomes intractable as $N$ becomes large, even for the simplest case where the coefficients $\left\{a_{i j}\right\}$ are constants.

Below, we propose a model that can capture contagion across an arbitrarily large number of firms. ${ }^{13}$ While our model can be interpreted as capturing counter-party risk as in JY, it will be most natural to interpret it as capturing contagion through Bayesian updating of beliefs. Most importantly, it will provide a tractable framework even when the number of firms sharing in the contagion is large. Before we introduce the model, however, we provide a simple framework that suggests jump-to-default premia have an upper bound of a few basis points if the pricing kernel can be proxied by returns on the market portfolio.

\section{Comparing Jump Risk Premia and Contagion Premia}

In this section, we investigate within a general equilibrium production economy the relative sizes of jump risk premia and contagion premia when there are a large number of "firms" $N$. Recall that JLY used APT-like arguments to show that if the jump-risk is conditionally diversifiable, and $N$ becomes large, then the jump risk premia goes to zero. Here, we generalize their results by allowing for contagion risk. Jump-risk will thus not be conditionally diversifiable in this model.

We consider a production economy with linear technologies as in Cox, Ingersoll and Ross (1985) and Ahn and Thompson (1988). For reasons of tractability, we consider $N$ identical production technologies with return dynamics: ${ }^{14}$

$$
\frac{d S_{i}}{S_{i}}=\mu d t+\sigma_{0} d z+\sigma_{i} d z_{i}-\Gamma_{D}\left(d q_{i}-\lambda^{P} d t\right)-\Gamma_{C} \sum_{j \neq i}^{N}\left(d q_{j}-\lambda^{P} d t\right),
$$

\footnotetext{
${ }^{13}$ We also prove below that in our framework,

$$
\mathrm{E}_{0}^{Q}\left[e^{-\int_{0}^{T} d s r(s)} \mathbf{1}_{\{\tau>T\}}\right] \neq \mathrm{E}_{0}^{Q}\left[e^{-\int_{0}^{T} d t\left(r(t)+\lambda^{Q}(t)\right)}\right] \mathbf{1}_{\{\tau>0\}}
$$

${ }^{14}$ We emphasize that choosing identical firm dynamics does not generate our results, but only makes the argument more transparent. As the APT literature has shown previously, similar arguments hold for the 'typical firm' so long as each firm is 'small'.
} 
where $d z$ is a Brownian motion common to all firms, the $\left\{d z_{i}\right\}$ are idiosyncratic Brownian motions orthogonal to each other and to $d z$, and the $\left\{d q_{i}\right\}$ are Poisson random variables with intensity $\lambda^{P}$. The term $\Gamma_{D} d q_{i}$ is meant to capture a "credit event" associated with firm- $i$, whereas the term $\Gamma_{C} d q_{j \neq i}$ is meant to capture firm- $i$ 's contagious response to a "credit event" associated with investment- $j$. As such, we anticipate $\Gamma_{D}>\Gamma_{C}$. That is, we expect the credit event associated with firm- $i$ to affect returns on firm- $i$ significantly more than the returns on the overall index. As we will see in Tables 1-3 below, this result occurs naturally in our framework.

Assume that the representative agent in the economy maximizes her expected utility:

$$
J(W, s)=\max \mathrm{E}\left[\int_{s}^{\infty} e^{-\delta(t-s)} \frac{C(t)^{1-\gamma}}{1-\gamma} d t\right]
$$

subject to her budget constraint

$$
\begin{aligned}
d W_{t}= & \left\{r W_{t}-C_{t}+W_{t}\left(\sum_{i=1}^{N} \pi_{i}\right)\left[(\mu-r)+\lambda^{P}\left(\Gamma_{D}+(N-1) \Gamma_{C}\right)\right]\right\} d t+W_{t} \sigma_{0}\left(\sum_{i=1}^{N} \pi_{i}\right) d z \\
& +W_{t} \sigma_{1}\left(\sum_{i=1}^{N} \pi_{i} d z_{i}\right)-W_{t}\left(\Gamma_{D}-\Gamma_{C}\right)\left(\sum_{i=1}^{N} \pi_{i} d q_{i}\right)-W_{t} \Gamma_{C}\left(\sum_{i=1}^{N} \pi_{i}\right) \sum_{j=1}^{N} d q_{j} .
\end{aligned}
$$

Here, we have defined $\pi_{i}$ to be the proportion of wealth placed into investment technology $i$. Note that the budget constraint implicitly assumes the existence of a risk-free security. However, in the end, the risk free rate $r_{t}$ will be chosen so that the representative agent holds this security in zero net supply (Cox, Ingersoll, Ross (1985)).

Applying Ito's lemma, the value function $J(W, t)$ satisfies the HJB equation:

$$
\begin{aligned}
0=\max _{C, \pi}\{ & e^{-\delta t} \frac{C^{1-\gamma}}{1-\gamma}+J_{t}+J_{W}\left[r W_{t}-C_{t}+W_{t}\left(\sum_{i=1}^{N} \pi_{i}\right)\left[(\mu-r)+\lambda^{P}\left(\Gamma_{D}+(N-1) \Gamma_{C}\right)\right]\right] \\
& +\frac{1}{2} W^{2} J_{W W}\left[\sigma_{0}^{2}\left(\sum_{i=1}^{N} \pi_{i}\right)^{2}+\sigma_{1}^{2}\left(\sum_{i=1}^{N} \pi_{i}^{2}\right)\right] \\
& \left.+\lambda^{P} \sum_{i=1}^{N}\left[J\left(W-W\left(\Gamma_{D}-\Gamma_{C}\right) \pi_{i}-W \Gamma_{C}\left(\sum_{i^{\prime}=1}^{N} \pi_{i^{\prime}}\right)\right)-J(W)\right]\right\}
\end{aligned}
$$

The first order condition are:

$$
\begin{aligned}
\frac{\partial}{\partial C}: & 0 & =e^{-\delta t} C_{t}^{-\gamma}-J_{W} \\
\frac{\partial}{\partial \pi_{k}}: & 0 & =W_{t} J_{W}\left[(\mu-r)+\lambda^{P}\left(\Gamma_{D}+(N-1) \Gamma_{C}\right)\right]+W^{2} J_{W W}\left[\sigma_{0}^{2}\left(\sum_{i=1}^{N} \pi_{i}\right)+\sigma_{1}^{2} \pi_{k}\right]
\end{aligned}
$$




$$
-\lambda^{P} W \sum_{i=1}^{N}\left\{J^{\prime}\left(W-W\left(\Gamma_{D}-\Gamma_{C}\right) \pi_{i}-W \Gamma_{C}\left(\sum_{j=1}^{N} \pi_{j}\right)\right)\left[\left(\Gamma_{D}-\Gamma_{C}\right) \mathbf{1}_{(i=k)}+\Gamma_{C}\right]\right\} .
$$

Due to the symmetric nature of all returns, and due to the fact that in equilibrium the risk free rate $r$ will adjust so that the bond is held in zero net supply, it follows that the agent will place a constant fraction of her wealth in each investment technology: $\pi_{i}=\frac{1}{N} \forall i$. Hence, ignoring idiosyncratic volatility, wealth dynamics simplify to

$$
\frac{d W_{t}}{W_{t}}=\left(\mu-\frac{C_{t}}{W_{t}}\right) d t+\sigma_{0} d z-\left[\left(\frac{1}{N}\right) \Gamma_{D}+\left(\frac{N-1}{N}\right) \Gamma_{C}\right] \sum_{i=1}^{N}\left[d q_{i}-\lambda^{P} d t\right] .
$$

As we discuss below, the main findings of this section are due to the functional form of the coefficient multiplying the jump processes, $\left[\left(\frac{1}{N}\right) \Gamma_{D}+\left(\frac{N-1}{N}\right) \Gamma_{C}\right]$.

It is well known that the solution to the indirect utility function takes the form

$$
J(W, t)=e^{-\delta t} A^{-\gamma} \frac{W^{1-\gamma}}{1-\gamma} .
$$

Therefore, we can express marginal utility dynamics (which takes on the role of pricing kernel in this model) as

$$
\frac{d J_{W}}{J_{W}}=-r d t-\gamma \sigma_{0} d z-\gamma \frac{\sigma_{1}}{N} \sum_{i=1}^{N} d z_{i}+\left\{\left[1-\frac{1}{N}\left(\Gamma_{D}+(N-1) \Gamma_{C}\right)\right]^{-\gamma}-1\right\} \sum_{i=1}^{N}\left[d q_{i}-\lambda^{P} d t\right] .
$$

One implication of this result is that the "credit events" $\left\{d q_{i}\right\}$ are priced, since they show up in the pricing kernel. Moreover, as can be seen in analogy with equations (3) and (8), the ratio of the risk-neutral intensity to the actual intensity $\left(\frac{\lambda^{Q}}{\lambda^{P}}\right)$ can be expressed as

$$
\left(\frac{\lambda^{Q}}{\lambda^{P}}\right)=\left[1-\frac{1}{N}\left(\Gamma_{D}+(N-1) \Gamma_{C}\right)\right]^{-\gamma}
$$

Plugging equation (22) into the consumption first order condition, we see that the priceconsumption ratio is a constant:

$$
C=A W
$$

More relevant for the issue at hand, plugging equation (22) into the portfolio weight first order condition, we find that the equilibrium excess return for each investment technology follows

$$
(\mu-r)=\gamma\left(\sigma_{0}^{2}+\frac{\sigma_{1}^{2}}{N}\right)+\lambda^{P}\left[\Gamma_{D}+(N-1) \Gamma_{C}\right]\left\{\left[1-\frac{1}{N}\left(\Gamma_{D}+(N-1) \Gamma_{C}\right)\right]^{-\gamma}-1\right\} .
$$


Equation (25) has a straightforward interpretation: The first term on the right hand side is the contribution to excess return due to the diffusion sources of risk $\left(d z,\left\{d z_{i}\right\}\right)$ :

$$
(\mu-r)_{d i f f u s i o n}=\gamma\left(\sigma_{0}^{2}+\frac{\sigma_{1}^{2}}{N}\right) .
$$

As in the standard diffusive model, the diffusion premium is a combination of relative risk aversion $\gamma$ and market variance. Consistent with standard APT arguments, we see that the idiosyncratic diffusive component $\left(\gamma \frac{\sigma_{1}^{2}}{N}\right)$ becomes negligible as the number of firms $N$ increases.

The second term on the right hand side is the contribution of excess return due to the jump sources of risk $\left(\left\{d q_{i}\right\}\right)$. It is useful to decompose this second term into a jump-risk component and a contagion-risk component:

$$
\begin{aligned}
(\mu-r)_{j u m p} & =\lambda^{P} \Gamma_{D}\left\{\left[1-\frac{1}{N}\left(\Gamma_{D}+(N-1) \Gamma_{C}\right)\right]^{-\gamma}-1\right\} \\
(\mu-r)_{\text {contagion }} & =\lambda^{P}(N-1) \Gamma_{C}\left\{\left[1-\frac{1}{N}\left(\Gamma_{D}+(N-1) \Gamma_{C}\right)\right]^{-\gamma}-1\right\} .
\end{aligned}
$$

It is worth noting that when the contagion-risk parameter $\Gamma_{C}$ is greater than zero, then a jump-event leads to a market-wide response in returns, and both components contribute to investment returns. However, if $\Gamma_{C}=0$, then not only is the contagion-risk zero (by definition), but the jump-component of excess return also vanishes as $N$ becomes large:

$$
\begin{aligned}
\left.(\mu-r)\right|_{j u m p, \Gamma_{C}=0} & =\lambda^{P} \Gamma_{D}\left\{\left[1-\frac{\Gamma_{D}}{N}\right]^{-\gamma}-1\right\} \\
& \stackrel{N}{\approx}\left(\frac{1}{N}\right) \lambda^{P} \gamma \Gamma_{D}^{2} .
\end{aligned}
$$

That is, without contagion risk, jump-to-default becomes idiosyncratic, and its associated risk premium falls as $\sim\left(\frac{1}{N}\right)$, just as the idiosyncratic volatility term does in equation (26). Hence, JTD premia can be sizeable only if contagion risk is sizeable.

Now, let us calibrate this model using equation (25). We emphasize that, up to this point, we have not characterized the size of the jump $\Gamma_{D}$ in equation (15). Historically, recovery rates on corporate bonds has been approximately $40 \% .{ }^{15}$ Hence, when investigating jump-todefault, we set $\Gamma_{D}=0.6$. Separately, in our empirical section, we investigate credit events where a firm's bond price fell on average by $10 \%$, so when studying that case, we set $\Gamma_{D} \approx .10$. Throughout, we set $N=1000$, since there were approximately $10^{3}$ firms with investment-grade status over the time period that we investigate empirically.

\footnotetext{
${ }^{15}$ See Moody's (2005) Report.
} 
Historically, the non-callable BBB-Treasury spread on 4-year debt has been estimated to be about 150bp (See, for example, Huang and Huang (2003), Chen et al (2009)). Approximately $20-25 \mathrm{bp}$ of that spread covers historical losses, ${ }^{16}$ so, conservatively, the risk premium has been approximately 125bp. Here, we look for an upper bound for the jump-to-default risk premium, so we set the diffusion premium to zero. Thus, the entire $125 \mathrm{bp}$ risk premium is being attributed to contagion risk and jump-to-default risk only. In Tables 1-3, we decompose the risk premium for these two components for different values of the risk aversion coefficient $\gamma$ for an economy with $N=1000$ investment technologies. In particular, using equation (25) and setting the volatility components to zero, we identify the implicit value for the contagion risk parameter $\Gamma_{C}$, and in turn, the contagion premium and jump-to-default premium. To calibrate this model, we use the historical one year default rate for BBB rated bonds of $0.2 \%$ obtained from Moody's. ${ }^{17}$ As an upper bound, we set the instantaneous default intensity to $\lambda^{P}=0.002$.

We find that for risk aversion coefficients ranging from $\gamma=5$ to $\gamma=20$, we can attribute only $2.7 \mathrm{bp}$ to $5.6 \mathrm{bp}$ of risk premium to jump-to-default risk - the remaining $120 \mathrm{bp}$ being attributed to contagion risk. Accounting for realistic levels of diffusion risk, liquidity risk, taxes, etc., reduces this number even further. Indeed, if instead of (BBB-Treasury) spread, we begin with credit default swap data, which reduces the spread to approximately 100bp, and then subtract $20-25 \mathrm{bp}$ for expected losses and $20 \mathrm{bp}^{18}$ for diffusion risk, then we obtain a conservative estimate of 55bp for "unexplained risk premium". Under this more realistic calibration, we find that the premium due to jump-risk varies from $1.8 \mathrm{bp}$ to $3.6 \mathrm{bp}$ as we go from $\gamma=5$ to $\gamma=20$. As a final example more closely related to our empirical work, if instead of jumps-to-default, we consider jumps in spreads that generate a $10 \%$ loss in the bond (i.e., $\Gamma_{D}=0.10$ ), with an intensity equal to our empirical estimate of $0.2 \%$, we find that the premium for jump-risk varies from $0.6 \mathrm{bp}$ to $1.2 \mathrm{bp}$ as we go from $\gamma=5$ to $\gamma=20$. Hence, there appears to be no reasonable calibration where jump-to-default risk is large when the number of firms $N$ is large. Instead, contagion risk must make up almost the entire unexplained risk premia, and thus can be quite large, as shown in Tables 1-3.

\footnotetext{
${ }^{16}$ See Moody's (2005) report, Elton (2001) et al.

${ }^{17}$ We emphasize that this intensity estimate significantly overestimates the historical intensity associated with default over a one month horizon. Indeed, we are aware of only a handful of firms that have defaulted with investment-grade status. Furthermore, the majority of these did not possess investment-grade spreads - that is, the market realized that these bonds were not truly investment-grade, and that the rating agencies were slow to downgrade.

${ }^{18} 20 \mathrm{bp}$ for diffusion risk is consistent with the findings of Driessen (2005) for a 10Y BBB bond.
} 
The interpretation of these results are as follows: The no arbitrage relation

$$
(\mu-r)=-\mathrm{E}\left[\frac{d \Lambda}{\Lambda} \frac{d P}{P}\right]
$$

implies that jump risk premia are a product of three numbers: i) the probability of a jump event, ii) the jump in the pricing kernel conditional on the event, and iii) the fractional loss conditional on the event. Equations (27)-(28) emphasize that jump premia and contagion premia, by definition, share the same pricing kernel jump $\left.\frac{d \Lambda}{\Lambda}\right|_{\text {jump }}=\left\{\left[1-\frac{1}{N}\left(\Gamma_{D}+(N-1) \Gamma_{C}\right)\right]^{-\gamma}-1\right\}$. The relative size of the jump component to the contagion component is the ratio $\frac{\lambda^{P} \Gamma_{D}}{(N-1) \lambda^{P} \Gamma_{C}}=$ $\frac{\Gamma_{D}}{(N-1) \Gamma_{C}}$. Even though we estimate $\Gamma_{D}$ to be approximately thirty times larger than $\Gamma_{C}$, (i.e., the firm suffering the credit event performs 30-times worse than does the index which shares in the contagion), the typical bond is $(N-1) \approx 1000$-times more likely to suffer a contagion event than a credit event. Thus, the contagion risk premium is approximately $\frac{1000}{30} \approx$ thirty times larger than the jump-to-default premium. Interestingly, the range of ratios $\frac{\Gamma_{D}}{\Gamma_{C}} \in(22,47)$ found in this example matches well with our empirical findings, as we discuss below.

The reason these magnitudes necessarily occur in this framework is because the functional form of the pricing kernel implies that the JTD risk premia can be sizeable only if $\Gamma_{C}$ is sizeable. Indeed, taking a Taylor series approximation of the pricing kernel jump

$$
\begin{aligned}
{\left[1-\frac{1}{N}\left(\Gamma_{D}+(N-1) \Gamma_{C}\right)\right]^{-\gamma}-1 } & \approx \gamma\left(\frac{1}{N} \Gamma_{D}+\frac{(N-1)}{N} \Gamma_{C}\right) \\
& \approx \gamma \Gamma_{C}
\end{aligned}
$$

implies that equations (27)-(28) simplify to

$$
\begin{aligned}
(\mu-r)_{\text {jump }} & \approx \gamma \lambda^{P} \Gamma_{C} \Gamma_{D} \\
(\mu-r)_{\text {contagion }} & \approx \gamma \lambda^{P}(N-1) \Gamma_{C}^{2} .
\end{aligned}
$$

Note that the JTD premium is approximately linear, and the contagion premium quadratic, in $\Gamma_{C}$. These equations make transparent why the JTD premium $(\mu-r)_{\text {jump }}$ cannot be large: the product $\gamma \lambda^{P} \Gamma_{D} \approx 10^{-2}$ implies that we need $\Gamma_{C}>10^{-1}$ for JTD premia to be at least $10 \mathrm{bp}$, but with $N=1000$ such a magnitude would imply a contagion premium of $\gamma \lambda^{P}(N-1) \Gamma_{C}^{2} \approx$ $10 \Gamma_{C}^{2} \approx 1000 \mathrm{bp}$ ! However, since observed bond premia are approximately $100 \mathrm{bp}$, we are forced to calibrate $\Gamma_{C}<0.03$, in turn leading to small JTD premia.

It is worth noting that, under this approximation, the pricing kernel is approximately proportional to the return on the aggregate index:

$$
\left.\frac{d J_{W}}{J_{W}}\right|_{\text {stoch }} \approx-\left.\gamma \frac{d W}{W}\right|_{\text {stoch }} .
$$


The implication is that if we can use returns on corporate bond indices to identify risk premia, then the argument above implies that JTD premia have an upper bound of a few basis points.

\section{A Tractable Model of Contagion-Risk}

In the previous section, we provided an argument that suggests that, whereas contagion risk premia can be substantial, JTD premia have an upper bound of a few basis points if expected bond returns can be explained in terms of covariation with corporate bond indices. Note that this situation ignores the possibility that jumps to default are priced because they impact, e.g., the stock market or aggregate consumption, without necessarily impacting corporate bond indices. Moreover, while the model provides simple and intuitive results, the assets considered are more readily interpreted as productive technologies rather than risky bonds with a specified maturity. In particular, the previous framework does not generate a term structure of credit spreads.

In this section, we specialize our focus to the pricing of risky bonds that jump to default. We then provide a tractable reduced form framework for pricing risky debt in the presence of contagion-risk in spite of the fact that many firms share in the contagion risk and that the model falls outside of the "no jump at default" condition.

Consider an economy where the true state of nature $\tilde{S}$ is unknown and can be in any one of $s \in(1, M)$ states. At date- $t$, investors do not know what state the economy is in, but form a prior $\pi_{s}(t) \equiv \operatorname{Prob}\left(\tilde{S}=s \mid \mathcal{F}_{t}\right)$, where $\mathcal{F}_{t}$ is the investors' information set at date- $t$. In this economy there are $N$ defaultable firms indexed by $i \in(1, N)$ with random default times $\tau_{i}$ driven by point processes characterized by default intensities. In particular, conditional upon being in state-s, the probability of default over the next interval $d t$ is expressed via

$$
\begin{aligned}
\operatorname{Pr}\left[d \mathbf{1}_{\left\{\tau_{i}<t\right\}}=1 \mid \tilde{S}=s, \mathcal{F}_{t}\right] & \equiv \mathrm{E}\left[d \mathbf{1}_{\left\{\tau_{i}<t\right\}} \mid \tilde{S}=s, \mathcal{F}_{t}\right] \\
& =\lambda_{i s}\left(t^{-}\right) \mathbf{1}_{\left\{\tau_{i}>t\right\}} d t .
\end{aligned}
$$

That is, we can interpret $\lambda_{i s}\left(t^{-}\right)$as the date- $t$ default intensity for firm- $i$ conditional upon being in state-s. Below, we will assume that, conditioning both on the state- $s$ and the paths $\left.\lambda_{i s}\left(t^{-}\right)\right|_{t=0} ^{T}$ for some distant future date- $T$, the default events across firms are independent. In technical terms, we are assuming a doubly-stochastic, or Cox-process conditional upon being in a particular state-s. ${ }^{19}$ We emphasize, however, because agents do not know the correct state- $s$, our model falls outside of the Cox-process framework, as will be made clear below in, for example, equation (44).

\footnotetext{
${ }^{19}$ See, for example, Lando (1998)
} 
Since investors do not know the actual state of nature, their estimate of the actual default intensity $\bar{\lambda}_{i}^{P}\left(t^{-}\right)$is defined implicitly through

$$
\begin{aligned}
\bar{\lambda}_{i}^{P}\left(t^{-}\right) \mathbf{1}_{\left\{\tau_{i}>t\right\}} d t & \equiv \mathrm{E}\left[d \mathbf{1}_{\left\{\tau_{i}<t\right\}} \mid \mathcal{F}_{t}\right] \\
& =\sum_{s=1}^{M} \pi_{s}(t) \mathrm{E}\left[d \mathbf{1}_{\left\{\tau_{i}<t\right\}} \mid \tilde{S}=s, \mathcal{F}_{t}\right] \\
& =\sum_{s=1}^{M} \pi_{s}(t) \lambda_{i s}\left(t^{-}\right) \mathbf{1}_{\left\{\tau_{i}>t\right\}} d t .
\end{aligned}
$$

Thus, conditional on investors' information, the default intensity of firm $i$ is equal to a weighted average of the conditional default intensities:

$$
\bar{\lambda}_{i}^{P}\left(t^{-}\right)=\sum_{s=1}^{M} \pi_{s}(t) \lambda_{i s}\left(t^{-}\right)
$$

We assume that investors continuously update their estimates of the $\left\{\pi_{s}(t)\right\}$ conditional upon whether or not they observe a default event during the interval $d t$. A direct application of Theorem 19.6 page 332 in Lipster and Shiryaev (see also their example 1 p. 333) gives the updating equation for $\pi_{s}(t):{ }^{20}$

$$
d \pi_{s}(t)=\pi_{s}(t) \sum_{i=1}^{N}\left[\left(\frac{\lambda_{i s}\left(t^{-}\right)}{\bar{\lambda}_{i}^{P}\left(t^{-}\right)}-1\right)\left(d \mathbf{1}_{\left\{\tau_{i} \leq t\right\}}-\bar{\lambda}_{i}^{P}\left(t^{-}\right) \mathbf{1}_{\left\{\tau_{i}>t\right\}} d t\right)\right] .
$$

We note that this process has many intuitive properties. First, if the prior $\pi_{s}(t)=1$ for some state- $s$ (and thus $\pi_{s^{\prime}}(t)=0$ for all other $s^{\prime}$ ), then there is no updating. That is, in an economy where the agents know for sure the intensity of the firms, then there is no learning to be done. Second, when no default is observed over an interval $d t$, then investors revise downward the 'high-default' states of nature (i.e., those $s$ with $\lambda_{i s}\left(t^{-}\right)>\bar{\lambda}_{i}^{P}\left(t^{-}\right)$), and in turn revise upward the 'low-default' states of nature (i.e., those $s$ with $\lambda_{i s}\left(t^{-}\right)<\bar{\lambda}_{i}^{P}\left(t^{-}\right)$). Conversely, when a default is observed over an interval $d t$, investors revise upward those high-default states of nature, and in turn revise downward those low-default states of nature. Third, note that $\pi_{s}(t) \equiv \mathrm{E}\left[\tilde{S}=s \mid \mathcal{F}_{t}\right]$ is a martingale in that $\mathrm{E}_{t}\left[d \pi_{s}(t)\right]=0$, as can be seen from equations (36) and (38). Indeed, it is convenient to rewrite equation (38) as

$$
\frac{d \pi_{s}(t)}{\pi_{s}(t)}=\sum_{i=1}^{N} \alpha_{i s}\left(t^{-}\right) d M_{i}(t)
$$

\footnotetext{
${ }^{20}$ We also provide a heuristic derivation of this result based solely on Bayes' rule in Appendix 8.2. We note that it would be straightforward to extend the model to allow for unobserved random transitions between states.
} 
where we have introduced $\alpha_{i s}\left(t^{-}\right) \equiv\left(\frac{\lambda_{i s}\left(t^{-}\right)}{\bar{\lambda}_{i}^{P}\left(t^{-}\right)}-1\right)$ and the martingale $M_{i}(t)$ with dynamics

$$
d M_{i}(t) \equiv\left(d \mathbf{1}_{\left\{\tau_{i} \leq t\right\}}-\bar{\lambda}_{i}^{P}(t) \mathbf{1}_{\left\{\tau_{i}>t\right\}} d t\right) .
$$

Finally, if we make the additional assumption that, for the typical firm- $i$, the conditional intensities $\lambda_{i s}(t)$ are increasing in $s$ :

$$
\lambda_{i 1}(t)<\lambda_{i 2}(t)<\ldots<\lambda_{i M}(t),
$$

then we can show that the default intensity $\bar{\lambda}_{i}(t)$ increases when some other 'typical' firm- $i$ ' defaults. Indeed, for the special case where the conditional intensities $\left\{\lambda_{i s}(t)\right\}$ are assumed to be constants, we can write

$$
\begin{aligned}
\left.d \bar{\lambda}_{i}^{P}(t)\right|_{\left(d \mathbf{1}_{\left\{\tau_{i^{\prime}}<t\right\}}=1\right)} & =\left.\sum_{s=1}^{M} \lambda_{i s} d \pi_{s}(t)\right|_{\left(d \mathbf{1}_{\left\{i_{i^{\prime}}<t\right\}}=1\right)} \\
& =\sum_{s=1}^{M} \lambda_{i s} \pi_{s}(t)\left(\frac{\lambda_{i^{\prime} s}(t)}{\bar{\lambda}_{i^{\prime}}^{P}(t)}-1\right) \\
& =\left(\frac{1}{\bar{\lambda}_{i^{\prime}}^{P}(t)}\right)\left\{\mathrm{E}_{s}\left[\lambda_{i} \lambda_{i^{\prime}}\right]-\mathrm{E}_{s}\left[\lambda_{i}\right] \mathrm{E}_{s}\left[\lambda_{i^{\prime}}\right]\right\} \\
& =\left(\frac{1}{\bar{\lambda}_{i^{\prime}}^{P}(t)}\right) \operatorname{Cov}\left[\lambda_{i}, \lambda_{i^{\prime}}\right] \\
& >0
\end{aligned}
$$

for firms $i, i^{\prime}$ satisfying equation (41).

The model specified by equations (37) and (38) is reminiscent of the counterparty risk example of JY given in equations (13)-(14) above in that the intensity of default $\bar{\lambda}_{i}^{P}(t)$ for firm- $i$ increases when some other firm- $k$ defaults. In contrast to JY, however, contagion is explicitly modeled as a result of the updating of beliefs. In addition to providing a mechanism for generating contagion in the absence of direct counter-party risk (such as in the Enron and RJR LBO events), the advantage of this framework is that it remains tractable even when the number of firms $N$ that share in the contagion is large. Indeed, we find that the survival probability for any firm- $i$ is given by:

$$
\begin{aligned}
\mathrm{E}\left[\mathbf{1}_{\left\{\tau_{i}>T\right\}} \mid \mathcal{F}_{t}\right] & =\sum_{s=1}^{M} \pi_{s}(t) \mathrm{E}\left[\mathbf{1}_{\left\{\tau_{i}>T\right\}} \mid \tilde{S}=s, \mathcal{F}_{t}\right] \\
& =\sum_{s=1}^{M} \pi_{s}(t) \mathrm{E}\left[e^{-\int_{t}^{T} \lambda_{i s}(u) d u} \mid \mathcal{F}_{t}\right]
\end{aligned}
$$


We emphasize that the survival probabilities in equation (43) are not equal to ${ }^{21}$

$$
\mathrm{E}\left[\mathbf{1}_{\left\{\tau_{i}>T\right\}} \mid \mathcal{F}_{t}\right] \neq \mathrm{E}\left[e^{-\int_{t}^{T} \bar{\lambda}^{P}(u) d u} \mid \mathcal{F}_{t}\right] .
$$

This result follows from the fact that the intensity of default for firm- $i$ jumps at the same date that the default occurs. That is, our model falls outside of the 'no-jump' framework of DSS, or the Cox-process framework of Lando (1998), and Duffie and Singleton (DS 1999).

Not only does our framework tractably account for a large number of firms sharing in the contagion, but, as we demonstrate below, our framework remains tractable even if the intensities $\left\{\lambda_{i s}(t)\right\}$ follow affine or squared-Gaussian stochastic processes. ${ }^{22}$ Moreover, one can easily choose dynamics to maintain the ordering implied in equation (41). For example, if the $\left\{\lambda_{i s}(t)\right\}$ are specified as

$$
\lambda_{i s}(t)=a_{i s}+\left(b_{i s}\right)^{\top} X_{i}(t)
$$

with positive constants $a_{i s}$, positive vectors $b_{i s}$, and $X_{i}(t)>0$ generated from square root dynamics (Duffie and Kan (1996)), ordering is maintained if the constraints $\left(a_{i 1}, b_{i 1}\right)<\left(a_{i 2}, b_{i 2}\right)<$ $\ldots<\left(a_{i M}, b_{i M}\right)$ are imposed. Alternatively, we can specify intensity dynamics as

$$
d \lambda_{i s}(t)=\kappa_{i}\left(\theta_{i s}-\lambda_{i s}(t)\right) d t+v_{i} \sqrt{\lambda_{i s}(t)} d Z_{i}(t),
$$

where the constraints $\left(\lambda_{i 1}(0), \theta_{i 1}\right)<\left(\lambda_{i 1}(0), \theta_{i 2}\right)<\ldots<\left(\lambda_{i M}(0), \theta_{i M}\right)$ are imposed. ${ }^{23} \mathrm{We}$ use this alternative below. In both examples, survival probabilities and the prices of typical defaultable claims, such as risky bonds and credit derivatives, can be obtained in closed-form at little additional cost over and above the traditional framework that ignores contagion. This feature is essential if one wishes to price, for example, collateralized debt obligations in a model that captures contagion over a large number of firms.

Although the model presented above is a reduced-form model, it is easily reconciled with the structural framework following the intuition of Duffie and Lando (DL 2000). DL show that, in contrast to a standard structural model (e.g., Merton (1974)), if the underlying firm value is imperfectly observed by investors, then from their point of view the default time becomes inaccessible in that default arrives as a surprise event. Our framework can be interpreted as an extension of DL's model to multiple firms that share a common (but unknown) accounting

\footnotetext{
${ }^{21} \mathrm{~A}$ proof is provided in appendix 8.3

${ }^{22}$ The affine restriction on the $\left\{\lambda_{i s}(t)\right\}$ is useful only for obtaining closed form solutions for prices or survival probabilities. The filtering equation for the prior $\pi_{s}(t)$ holds for arbitrary (positive integrable) conditional intensity processes.

${ }^{23}$ That these conditions are sufficient to insure the ordering of intensities across states follows immediately from the following observation. Suppose, $\lambda_{i s}(0)>\lambda_{i s^{\prime}}(0)$. The only way the order can change is if $\lambda_{i s}(t)=\lambda_{i s^{\prime}}(t)$ at some $t>0$ (because of their sample paths are continuous). But then $d\left(\lambda_{i s}(t)-\lambda_{i s^{\prime}}(t)\right)=\kappa_{i}\left(\theta_{i s}-\theta_{i s^{\prime}}\right) d t>0$.
} 
accuracy. ${ }^{24}$ The unexpected default of one firm will trigger an updating of beliefs by investors about the shared 'accounting quality', and hence will affect the perceived likelihood of default of other firms in the economy.

Up to this point, the state variable dynamics have been specified under the historical measure. In the following section we address the issue of pricing defaultable securities in the presence of contagion risk and systematic jump risk.

\section{$5 \quad$ Pricing Risky Bonds}

The framework in the previous section assumes that agents are uncertain about the level of default risk in the economy, and that they learn about the fundamental state from the history of observed defaults. Given the rarity of the latter, it is natural to assume that agents are particularly concerned about estimation errors when assessing the state. To allow for such a concern (and the associated potential source of risk-adjustment), we build on the fragile beliefs framework of Hansen and Sargent (2009) and Hansen (2007). Specifically, we specify that aggregate consumption follows a jump-diffusion process where the jump intensity (and therefore, the expected consumption growth) depends upon a hidden state. As shown by Hansen and Sargent (2009), if agents have fragile beliefs about their estimate of the state, then learning dynamics carry specific risk-premia. Here we extend their model by allowing agents to use other sources of information in addition to past aggregate consumption to learn about the state. Specifically, in our model agents also learn from realized default events, since states with high default rates and, in turn, high credit spreads, are associated with low expected consumption growth. ${ }^{25}$ Even though consumption does not jump contemporaneously with default events, the concern for fragility generates a risk-premium associated with the probabilities of being in the different states. In particular, as can be seen in equations (61) and (62) below, asset prices are equal to weighted averages of prices conditional upon being in state- $s$. However, those states of nature associated with higher expected default rates/lower expected consumption growth will be weighted more heavily. That is, in regards to pricing, fragile preferences will effectively tilt 'risk-neutral' probabilities toward poorer economic states. The implication is that risk-neutral contagion, i.e., price contagion, may be significantly larger than the level of contagion implied under the empirical measure. Interestingly, even though the representative agent displays fragility, his marginal valuation is dynamically-consistent,

\footnotetext{
${ }^{24}$ This model is available upon request.

${ }^{25}$ Consistent with our model, Gilchrist, Yankov and Zakrajsek (2009) demonstrate that credit spreads predict future GDP growth.
} 
implying that we can price long-dated claims using the gradient of the agent's marginal utility. ${ }^{26}$

We assume that the aggregate dividend, which in this exchange economy will equal aggregate consumption, follows the jump-diffusion process

$$
d \log C_{t}=\mu d t+\sigma d Z(t)-\Gamma d N_{0},
$$

where the intensity of the Poisson process $d N_{0}$ is state-dependent:

$$
\mathrm{E}\left[d N_{0} \mid s\right]=\lambda_{0, s} d t
$$

Hence, expected consumption growth is also state-dependent:

$$
\left(\frac{1}{d t}\right) \mathrm{E}\left[d \log C_{t} \mid \tilde{S}_{t}=s\right]=\mu-\Gamma \lambda_{0, s},
$$

implying that unconditional expected consumption growth follows

$$
\begin{aligned}
\left(\frac{1}{d t}\right) \mathrm{E}\left[d \log C_{t}\right] & =\mu-\Gamma\left(\sum_{s} \pi_{s}(t) \lambda_{0, s}\right) \\
& =\mu-\Gamma \bar{\lambda}_{0}^{P}(t) .
\end{aligned}
$$

In the previous literature (e.g., David (1997) and Veronesi (2000)), agents update their estimate of the state likelihood $\pi_{s}(t)$ based solely on their observation of aggregate consumption. ${ }^{27}$ In contrast to these papers, we allow agents to update their beliefs regarding the state of nature using information from both aggregate consumption and the realized history of defaults. In particular, agents will attribute a greater probability of being in poor economic states upon observing either a jump in aggregate consumption $N_{0}(t)$ or a jump-to-default of an individual firm. Hence, the dynamics for the $\left\{\pi_{s}\right\}$ generalize from equation (39) by including learning from observing consumption:

$$
d \pi_{s}(t)=\pi_{s}(t) \sum_{i=0}^{N} \alpha_{i s}\left(t^{-}\right) d M_{i}(t),
$$

where we have used the notation

$$
\alpha_{i 0}\left(t^{-}\right) d M_{0}(t)=\left(\frac{\lambda_{0, s}}{\bar{\lambda}_{0}^{P}}-1\right)\left(d N_{0}-\bar{\lambda}_{0}^{P} d t\right) .
$$

\footnotetext{
${ }^{26}$ Collin-Dufresne and Goldstein (2009) show that the $T_{2}$ operator of Hansen and Sargent (HS 2007) leads to dynamically consistent preferences if it is combined with a $T_{1}$ operator that displays time-separable homothetic preferences. This result is in contrast to the approach of HS (2007), where one needs to solve recursively the one-period pricing problem in order to price long-dated claims, which is numerically cumbersome.

${ }^{27}$ In David (1997) and Veronesi (2000), consumption follows a diffusion process, in contrast to the jumpdiffusion process studied here. However, this is merely a technical difference.
} 
We note that in time-separable frameworks such as David (1997) and Veronesi (2000), jumps in the $\left\{\pi_{s}\right\}$, which imply jumps in the expected growth rate of consumption, do not carry a risk-premium, since changes in their pricing kernel $U^{\prime}(c) \sim C(t)^{-\gamma}$ are generated only by contemporaneous changes in consumption, and not changes in the expected growth rate. However, in the fragile beliefs framework, these jumps will be priced. In particular, we assume a representative agent with the following preferences:

- Conditional upon observing state $s \in(1, M)$, the agent has log-preferences. That is, the agent ranks consumption lotteries in state- $s$ according to the (state contingent) index $V\left(\mathcal{F}_{t} \mid s\right)$, which satisfies:

$$
V\left(\mathcal{F}_{t} \mid s\right)=\left(1-e^{-\beta d t}\right) \log C_{t}+e^{-\beta d t} \mathrm{E}_{t}\left[V\left(\mathcal{F}_{t+d t} \mid s\right)\right] .
$$

- To rank consumption streams unconditionally, the agent displays fragile beliefs. That is, the agent combines the conditional utility indices using a preference for robustness parameter $\zeta$ via:

$$
V\left(\mathcal{F}_{t}\right)=\min _{\xi_{s}>0, \sum_{s} \pi_{s} \xi_{s}=1}\left\{\sum_{s=1}^{M} \pi_{s}(t)\left(\xi_{s} V\left(\mathcal{F}_{t} \mid s\right)+\zeta \xi_{s} \log \xi_{s}\right)\right\},
$$

where we have used the shorthand notation $\xi_{s}=\xi\left(s \mid \mathcal{F}_{t}\right)$.

Hence, to solve for the preferences of this agent, we first need to solve for the conditional utility in equation (53), and then solve for the fragile beliefs in equation (54).

\subsection{Conditional Log-Utility}

The solution to equation (53) is standard (e.g., Hansen (2007)):

$$
V\left(\mathcal{F}_{t} \mid s\right)=\log C_{t}+B_{s},
$$

where, by plugging this trial solution into equation (53), we find

$$
B_{s}=\frac{\mu-\Gamma \lambda_{0 s}}{\beta} \text {. }
$$

The pricing kernel conditional on being in state- $s$ is given by:

$$
\Lambda^{s}(t)=e^{-\beta t} e^{-\log C(t)} .
$$

Its dynamics follow:

$$
\frac{d \Lambda^{s}(t)}{\Lambda^{s}(t)}=-r^{s} d t-\sigma d Z(t)+\left(e^{\Gamma}-1\right) d M_{0}(t)
$$

where the state-contingent spot rate equals

$$
r^{s}=\beta+\mu-\frac{\sigma_{c}^{2}}{2}-\lambda_{0 s}\left(e^{\Gamma}-1\right) .
$$




\section{$5.2 \quad$ Fragile Beliefs}

Given the solution to the conditional utility in equation (55), we can then solve for the utility of the fragile-beliefs agent. The fragility risk-adjustment for the state is given by:

$$
\xi_{s}(t)=\frac{e^{-\frac{B_{s}}{\zeta}}}{\sum_{s} e^{-\frac{B_{s}}{\zeta}} \pi_{s}(t)}
$$

It therefore follows that the present value $P(X)$ of a future random cash-flow $\tilde{X}_{T}$ paid at time $T$ to a fragile beliefs investor is equal to: ${ }^{28}$

$$
P(X)=\sum_{s=1}^{M} \pi_{s}^{Q}(t) \mathrm{E}_{t}\left[\left(\frac{\Lambda^{s}(T)}{\Lambda^{s}(t)}\right) X_{T} \mid S_{t}=s\right]
$$

where the tilted (or 'risk neutral') probabilities $\pi_{s}^{Q}(t)$ are defined via

$$
\pi_{s}^{Q}(t)=\pi_{s}(t) \xi_{s}(t)
$$

\subsection{Pricing kernel}

This framework, which builds on Hansen and Sargent (2007), combines fragility (their $T_{2}$ operator) with time-separable utility conditional on a state. Collin-Dufresne and Goldstein (2009) show that such a framework is dynamically-consistent, implying that prices of securities with long-dated cash flows can be supported by a pricing kernel with the following dynamics:

$$
\frac{d \Lambda(t)}{\Lambda(t)}=-r(t) d t-\sigma d Z(t)+\sum_{i=1}^{n}\left(\frac{\bar{\lambda}_{i}^{Q}-\bar{\lambda}_{i}^{P}}{\bar{\lambda}_{i}^{P}}\right) d M_{i}(t)+\left(\frac{\bar{\lambda}_{0}^{Q} e^{\Gamma}-\bar{\lambda}_{0}^{P}}{\bar{\lambda}_{0}^{P}}\right) d M_{0}(t)
$$

where we have defined

$$
\begin{aligned}
r(t) & \equiv \sum_{s} \pi_{s}^{Q}(t) r^{s} \\
\bar{\lambda}_{i}^{Q} & \equiv \sum_{s} \pi_{s}^{Q}(t) \lambda_{i s}(t) .
\end{aligned}
$$

Here we price two types of securities with long-dated cash flows: (i) the risk-free zerocoupon curve, and (ii) the risky (defaultable) zero-coupon curve.

\footnotetext{
${ }^{28} \mathrm{In}$ an earlier version of this paper, we exogenously specified the pricing kernel to be a sum of terms linear in $\pi_{s}(t)$ (and $\pi_{s}^{Q}(t)$ ). The preferences of Hansen (2007) provide a general equilibrium justification for such a specification.
} 
5.4 The Risk-free zero-coupon bond with maturity $T$ (i.e., $\tilde{X}=1$ ).

The zero-coupon bond price is:

$$
\begin{aligned}
P(t, T) & =\mathrm{E}_{t}\left[\frac{\Lambda(T)}{\Lambda(t)}\right] \\
& =\sum_{s=1}^{M} \pi_{s}^{Q}(t) \mathrm{E}_{t}\left[\frac{\Lambda^{s}(T)}{\Lambda^{s}(t)} \mid s\right] \\
& =\sum_{s=1}^{M} \pi_{s}^{Q}(t) e^{-(T-t) r^{s}} .
\end{aligned}
$$

Note that zero-coupon bond prices are convex combinations of standard exchange economies with a log-investor. In particular, the short end of the risk-free zero-coupon curve is given by:

$$
r(t)=-\left.\frac{\partial \log P(t, T)}{\partial(T-t)}\right|_{(T-t) \rightarrow 0}=\sum_{s=1}^{M} \pi_{s}^{Q}(t) r^{s} .
$$

\subsection{Defaultable zero-coupon bond price $\tilde{X}=\mathbf{1}_{\left\{\tau_{i}>T\right\}}$.}

We assume that the default intensity of firm $i \in(1, N)$ in a state $s$ follows a CIR process:

$$
d \lambda_{i s}(t)=\kappa_{i}\left(\theta_{i s}-\lambda_{i s}(t)\right) d t+v_{i} \sqrt{\lambda_{i s}(t)} d Z_{i}(t)
$$

with $\left(\theta_{i s}>\theta_{i s^{\prime}}\right)$ and $\left(\lambda_{i s}(0)>\lambda_{i s^{\prime}}(0)\right)$ for those states $\left(s, s^{\prime}\right)$ that satisfy $\left(\lambda_{0 s}>\lambda_{0 s^{\prime}}\right)$. In other words, we specify the model so that long run default rates are higher in those states with lower expected growth rates for aggregate consumption. We assume the $Z_{i}(t)$ Brownian motions are uncorrelated across firms and with aggregate consumption. ${ }^{29}$

The defaultable zero-coupon bond price of firm $i$ is:

$$
\begin{aligned}
B^{i}(t, T) & =\mathrm{E}_{t}\left[\frac{\Lambda(T)}{\Lambda(t)} \mathbf{1}_{\left\{\tau_{i}>T\right\}}\right] \\
& =\sum_{s=1}^{M} \pi_{s}^{Q}(t) \mathrm{E}_{t}\left[\left(\frac{\Lambda^{s}(T)}{\Lambda^{s}(t)}\right) \mathbf{1}_{\left\{\tau_{i}>T\right\}} \mid s\right] \\
& =\sum_{s=1}^{M} \pi_{s}^{Q}(t) e^{-r^{s}(T-t)} \mathrm{E}_{t}\left[e^{-\int_{t}^{T} \lambda_{i s}(u) d u} \mid s\right] \mathbf{1}_{\left\{\tau_{i}>t\right\}} \\
& =\left[\sum_{s=1}^{M} \pi_{s}^{Q}(t) B_{s}^{i}(t, T)\right] \mathbf{1}_{\left\{\tau_{i}>t\right\}},
\end{aligned}
$$

\footnotetext{
${ }^{29}$ We can relax this assumption, but at the cost of increased model complexity. We have chosen to maintain this more parsimonious framework since our focus is on the relative size of contagion and JTD risk premia, and accounting for diffusion premia won't affect this.
} 
where

$$
B_{s}^{i}(t, T) \equiv e^{-(T-t) r^{s}+\mathcal{A}_{i, s}(T-t)-\mathcal{B}_{i}(T-t) \lambda_{i s}(t)}
$$

is the price of the risky bond conditional upon being in state-s, and where the deterministic functions $\mathcal{A}_{i, s}(\tau), \mathcal{B}_{i}(\tau)$ satisfy a system of ODE's solved in closed-form by Cox-Ingersoll and Ross (1985).

We see that as maturity goes to zero, credit spreads converge to:

$$
\lim _{(T-t) \rightarrow 0} \log \left(\frac{B^{i}(t, T)}{P(t, T)}\right)=\sum_{s=1}^{M} \pi_{s}^{Q} \lambda_{i s}(t) \equiv \bar{\lambda}_{i}^{Q}(t) .
$$

Note that this is greater than the expected loss

$$
\bar{\lambda}_{i}^{P}(t)=\sum_{s=1}^{M} \pi_{s}(t) \lambda_{i s},
$$

since we have assumed that intensities and expected consumption growth are negatively correlated. Indeed:

$$
\begin{aligned}
\bar{\lambda}_{i}^{Q}(t)-\bar{\lambda}_{i}^{P}(t) & =\sum_{s} \pi_{s} \xi_{s} \lambda_{i s}-\sum_{s} \pi_{s} \lambda_{i s} \\
& =\operatorname{cov}\left(\xi_{s}, \lambda_{i s}\right) \\
& >0,
\end{aligned}
$$

where we have used equations (56), (60) and $\sum_{s} \pi_{s} \xi_{s}=1$. Interpreting, the tilted Qprobabilities $\pi_{s}^{Q}(t)=\pi_{s}(t) \xi_{s}(t)$ used for pricing are higher than the actual probabilities $\pi_{s}(t)$ for those states- $s$ associated with low expected consumption growth and high expected default rates.

\subsection{Credit Risk Premium}

As in Section 3, we are interested in comparing the risk premia associated with jump-todefault risk and contagion risk. Because we assume that the Brownian motions $Z_{i}(t)$ which drive $\lambda_{i s}(t)$ are purely idiosyncratic, risky bonds command only jump risk-premia. Note that in this parsimonious model, the only state variables in this economy are the probabilities $\left\{\pi_{s}(t)\right\}$, which according to equation (38) update as $\pi_{s}(t) \stackrel{\text { jump }}{\Rightarrow} \pi_{s}(t)\left(\lambda_{i s}(t) / \bar{\lambda}_{i}^{P}(t)\right)$ when a jump occurs. Hence, a jump in either consumption or in firm- $i$ will generate a jump in the price of bond- $k$ of $B^{k}\left(\pi_{s}(t), t, T\right) \stackrel{\text { jump }}{\Rightarrow} B^{k}\left(\pi_{s}(t)\left(\lambda_{i s}(t) / \bar{\lambda}_{i}^{P}(t)\right), t, T\right)$.

The jump premia can be decomposed into three sources: (i) JTD premia, (ii) contagion premia, and (iii) premia due to consumption jumps. These last two channels impact the price 
of $B^{k}$ indirectly via its impact on the risk-adjusted probability of the state $\pi_{s}^{Q}(t) \equiv \pi_{s}(t) \xi_{s}(t)$. More formally, the excess return on any bond is given by:

$$
\begin{aligned}
\left(\mathrm{E}\left[\frac{d B^{k}(t, T)}{B^{k}(t, T)}\right]-r(t)\right) d t & =-\mathrm{E}\left[\frac{d \Lambda(t)}{\Lambda(t)} \frac{d B^{k}(t, T)}{B^{k}(t, T)}\right] \\
& =-\bar{\lambda}_{k}^{P}\left(\frac{\bar{\lambda}_{k}^{Q}-\bar{\lambda}_{k}^{P}}{\bar{\lambda}_{k}^{P}}\right)(-1)-\left.\sum_{i \neq k} \bar{\lambda}_{i}^{P}\left(\frac{\bar{\lambda}_{i}^{Q} e^{\Gamma \mathbf{1}_{\{i=0\}}-\bar{\lambda}_{i}^{P}}}{\bar{\lambda}_{i}^{P}}\right)\left(\frac{d B^{k}}{B^{k}}\right)\right|_{d \mathbf{M}_{i}=1} \\
& =\left(\bar{\lambda}_{k}^{Q}-\bar{\lambda}_{k}^{P}\right)+\sum_{i \neq k}\left(\bar{\lambda}_{i}^{Q} e^{\Gamma \mathbf{1}_{\{i=0\}}}-\bar{\lambda}_{i}^{P}\right)\left(1-\frac{B^{k}\left(\pi_{s}(t) \frac{\lambda_{i s}(t)}{\bar{\lambda}_{i}^{P}(t)}, t, T\right)}{B^{k}\left(\pi_{s}(t), t, T\right)}\right) .
\end{aligned}
$$

Here, the first term represents the JTD premium. The second term encompasses both the contagion premium $(i \in(i, N))$, and the premium for consumption jumps $(i=0)$.

\subsection{A Calibration exercise}

As opposed to the production economy of Section 3, jump to default is priced in this economy not because of its impact on the corporate bond portfolio, but rather because it lowers expected consumption growth via a learning channel. As such, JTD premia are not mechanically limited to a few basis points as they were in that model. Here, we investigate how large the JTD premium can be in a fragile beliefs framework.

For parsimony, we assume that there are only $S=2$ states. We therefore have ten parameters to calibrate: $\left(\mu, \Gamma_{G}, \Gamma_{B}, \sigma_{C}, \beta, \pi_{G}(t), \theta_{G}, \theta_{B}, \kappa, v, \zeta\right)$. We choose $\sigma_{C}$ to match historical consumption volatility of 0.02 , and $\mu$ to match historical consumption growth of $0.018 .{ }^{30}$ Although aggregate consumption is measured only quarterly, and with significant noise, we limited the size of jumps in consumption to 0.004. We also match well the historical (1Y, $5 \mathrm{Y}, 10 \mathrm{Y}, 20 \mathrm{Y})$ BBB cumulative default rates (obtained from Moody's) of (0.002, 0.021, 0.049, $0.121)$. We limit the volatility of short term credit spreads to $30 \mathrm{bp}$, and pricing kernel volatility to 100bp (twice the estimates of Lettau and Ludvigson (2001)).

In all of our calibrations we also impose that the contagion premium be positive, as it is consistent with our empirical results in the next section. This requires two things. First, we need to impose the ordering between default intensities and long run means discussed with equation (69), so that a default event implies bad news about future default probabilities. Second, we need that effect to dominate the risk-free rate effect. Indeed, interestingly, a default event triggers a "flight-to-quality", that is, a decrease in the risk-free rate as we update towards worse economic conditions. This has a positive impact on the prices of long-lived

\footnotetext{
${ }^{30}$ See, for example, Campbell and Cochrane (1999), Bansal and Yaron (2004).
} 
bonds through the discount channel, which could, in principle, dominate the negative effect of increased default likelihoods. We impose in our calibration (consistent with what we find empirically below) that the net effect is negative.

In all cases, we found the JTD premium to be under 7bp. The intuition is the following: from equation (63), pricing kernel variance is

$$
\left(\frac{1}{d t}\right) \mathrm{E}\left[\left(\frac{d \Lambda}{\Lambda}\right)^{2}\right]=\sigma^{2}+N\left(\frac{\bar{\lambda}_{i}^{Q}-\bar{\lambda}_{i}^{P}}{\bar{\lambda}_{i}^{P}}\right)^{2} \bar{\lambda}_{i}^{P}+\left(\frac{\bar{\lambda}_{0}^{Q} e^{\Gamma}-\bar{\lambda}_{0}^{P}}{\bar{\lambda}_{0}^{P}}\right)^{2} \bar{\lambda}_{0}^{P} .
$$

If we want to limit pricing kernel volatility (i.e., maximum Sharpe ratio) to be below 100bps, then it follows that, with $N=1000$ and $\bar{\lambda}_{i}^{P}=0.001$, we necessarily need $\left(\bar{\lambda}_{i}^{Q}-\bar{\lambda}_{i}^{P}\right)<\bar{\lambda}_{i}^{P}=$ 0.001 , or $10 \mathrm{bp}$. That is, just limiting the pricing kernel volatility to $100 \mathrm{bp}$ already limits the JTD premium $\left(\bar{\lambda}_{i}^{Q}-\bar{\lambda}_{i}^{P}\right)$ to under 10bp. Imposing the additional restrictions discussed above reduces this upper bound even further. We also, find that contagion risk tends to be more important at longer maturities than at short maturities and much larger than the JTD premium if the ratio of long-run default intensities is larger than its current value (i.e., $\left.\frac{\theta_{i B}}{\theta_{i G}}>\frac{\lambda_{i B}}{\lambda_{i G}}\right)$. The intuition for this result can be seen from the excess return equation (76). It shows that the JTD risk-premium is solely tied to the difference between instantaneous default intensities. However, the contagion premium is tied to the impact on surviving bond prices of an increased weight put on the bad state. That contagion price impact depends crucially on the ratio of long-run default intensities across states and more so for longer maturity bonds.

Ultimately, the magnitude of the contagion risk is not pinned down uniquely by our model (as it depends on the relative magnitude of parameters and in particular, on the long-run values of the default intensities across states). It is an empirical matter how large that effect is in the data. We turn to this next.

\section{Empirical Analysis}

We have shown that for JTD to be priced large credit events should have market wide implications either via direct contagion to bond portfolios (section (3)) or because they convey information about the "hidden" state of the economy (section (4)). In both cases, reasonable calibrations also imply that contagion risk premia should be more significant quantitatively, than JTD risk-premia. We explore these two implications in this section.

Our empirical work is motivated as follows: if credit events are priced, we expect the main source of risk to stem from events that are surprises to investors. Unexpected credit events, then, should be identifiable as those where an individual firm's bond exhibits a large 
jump in its spread. We therefore investigate empirically the impact that such credit events have on the market. In particular, if these events are priced, then we expect them to be associated with increases in aggregate credit spreads, and possibly also have a negative impact on equities. Furthermore, consistent with the implications of the general equilibrium framework in Section 5, we investigate whether such jumps are associated with 'flights-to-quality' affecting risk-free rates. ${ }^{31}$

Regardless of whether the contagion is due to 'counterparty risk' or to 'updating-of-beliefs', one would expect that jumps in the yield spreads of larger, 'safer' firms would produce a greater impact on the market portfolio than would credit events of 'riskier' firms, since such events would be less surprising. As such, we limit our empirical investigation to investment-grade bonds. We note that few investment-grade firms default while holding the rating. Thus, if these firms do eventually default, that event is likely to be anticlimactic and would not likely cause a market-wide response. Consequently, our credit events consist largely of jumps in spreads, not defaults.

\subsection{Data}

In order to gather a sufficiently large number of credit events in the investment-grade market, we use the Fixed Income Database (FID), which contains month-end trader quotes from January 1973-March 1998. These data have the advantage of reasonably good quality price data (see Warga (1991) and Warga and Welch (1993)) over a long time series.

We calculate corporate bond spreads as the difference between the bond's yield to maturity (YTM) and the interpolated YTM on a Treasury bond with a similar maturity. The Treasury yields are the Federal Reserve's Constant Maturity Treasury (CMT) daily series, using only yields from this series in time periods when the bond is actually auctioned. We use actual CMT yields when the corporate bonds have the same maturity as the CMT bonds and interpolated YTMs (using the Nelson-Siegel (1987) method) for the other maturities. ${ }^{32}$

We use trader quotes and delete matrix prices from the analysis, as suggested by Warga (1991). We consider spreads on all U.S. corporate bonds rated investment-grade in the FID as long as they are not private placements, medium term notes, or Euro-bonds. We delete offerings by government-sponsored enterprises and supranational organizations, as well as mortgagebacked or other asset-backed securities and bonds that are convertible into preferred stock.

\footnotetext{
${ }^{31}$ Note that we do not investigate incidences of major spread decreases, since the effect of these jumps on the 'market portfolio' is not expected to be symmetric.

${ }^{32}$ Nelson-Siegel interpolation requires estimates of the rate of decay of the regressors, $\tau$. We use 400 values of $\tau$ to obtain the most efficient estimate of the yield curve for each day in the sample. We use $\tau$ to create YTMs for each of 30 yearly maturities.
} 
We define a credit event as a major change in a bond's credit spread from one month to the next. Among the set of bonds that experience such shocks, we exclude bonds with less than two years until maturity. ${ }^{33}$ We also exclude bonds that have already fallen below a flat price of $\$ 80$ (which would be the second piece of bad news about the firm). Furthermore, we exclude bonds where the post-credit-shock price is above $\$ 95$. This exclusion helps avoid identifying a coding error as a credit-event. ${ }^{34}$

The FID does not readily identify floating rate bonds. Unnoticed, these bonds' spreads could be miscalculated, giving rise to spurious credit events when none occurred. We eliminate floating rate bonds from the sample by investigating their description in the Securities Data Corporation database and by checking that the standard deviation of a bond's coupon in the FID is zero.

With these qualifications, we obtain 52,828 instances where spreads widen. Table 4 shows the distribution of spread increases on corporate bonds in the FID over the sample period. The vast majority of the increases are quite small. Indeed, less than $3 \%$ are more than $50 \mathrm{bp}$. We wish to focus on rare events, yet we also wish to avoid small sample problems. Thus, we consider all spread increases of 200 bp or more (totalling 158 bonds) as credit events.

To avoid spurious results, we investigate each of these large spread changes in the financial press (Lexis-Nexus and Standard and Poor's Creditweek) to ascertain that a credit event actually occurred. Evidence of an event includes news of a bond rating downgrade, dividend cuts, major losses or other negative information in an earnings announcement, depressed stock prices, a major lawsuit or accident, a subsequent default or bankruptcy, or a leverage-increasing merger. If we cannot find evidence of a credit shock to the bond, we also check the bond price in Moody's Bond Record to see if a sale price exists at a level close to our bond price. If not, we assume it is a typo in the FID. Of the 158 bonds with wider spreads, we have evidence that 112 involve a credit event. These bonds belong to 40 firms, two of which suffered two episodes of credit risk (Chrysler and RJR Nabisco). The large number of bonds relative to the number of firms reflects the fact that many of the firms have numerous bonds outstanding.

Most of the credit events involve economic hardship. Many of these bonds belong to Chrysler, which suffered in the 1970's and again in 1990. Some of these occur during recession years. Another common event is a leveraged buyout (e.g., RJR Nabisco). The third largest

\footnotetext{
${ }^{33}$ We do so because a large jump in the YTM does not necessarily imply a large negative return on very short term bonds.

${ }^{34} \mathrm{~A}$ bond might be selling at a sizeable discount (e.g., below $\$ 80$ ) simply because yields have risen substantially since the bond was issued. Likewise, a bond may sell at a sizeable premium because yields have fallen since issuance, so that even if this bond suffers a credit event its price might remain above $\$ 95$. These types of errors would only reduce the likelihood of finding significant results.
} 
category includes banks that lent funds that are unlikely to be recovered, often because of real estate loans in the 1990-1991 recession or loans to Latin America in the early 1980s.

Some of the corporate bonds in our sample lost substantial value in one month, and then went on to lose additional value in ensuing months. Because it is conceivable that such bonds were no longer considered 'investment-grade' in the minds of the marketplace after the first event, we use only the first credit shock in a series of episodes. By a series of episodes, we mean more than one credit shock for a bond over the course of a year. We identify 25 months over the sample period in which a credit event first occurs. The remaining 273 months are not credit event months.

We compare these 25 credit event months with other months by examining how returns of aggregate portfolios differ when a credit event occurs. We investigate the impact on the Lehman corporate bond index, the CRSP value-weighted stock index (including all NYSE, AMEX and Nasdaq firms), and the Lehman Treasury index. Our initial analysis compares credit event months with other months using t-tests. Subsequent results control for other factors in regressions, including controlling for macroeconomic factors identified by Fleming and Remolona (1999) and other episodes of flight-to-quality (see Longstaff (2004)). We expect that credit events of large firms will have a greater impact on the market than those of small firms. We measure size by the amount of corporate bonds outstanding and by total assets. ${ }^{35}$

A major concern is whether our bonds constitute such a large fraction of the corporate bond index that their own price movements drive the returns on the Lehman index. This is unlikely as our events usually involve only a single firm in any given month. The month with the largest number of affected bonds is September 1990, during which 11 firms and 27 bonds are classified as experiencing a credit event. These do not drive the index, as 3811 corporate bonds are in the index that month. Furthermore, we find similar results (unreported) if we include only those months where a single firm suffered a credit shock.

\subsection{Results}

We first compare average returns in the Treasury, corporate bond and stock markets in the months in which credit events occur to the average returns during those months when no event occurred. We focus on returns to the corporate bond index in excess of Treasury returns. Table 5 shows that in the months in which a credit shock occurred the average excess return on the corporate bond index is negative and significantly lower than the return in the other

\footnotetext{
${ }^{35}$ Corporate bonds outstanding is the sum of bonds in the FID for the issuer's six-digit cusip, which can be inaccurate if cusips vary across a firm's bond issues. Total assets is for the year in which the credit event occurs and comes from Compustat, except for one firm whose assets are from Moody's Transportation Manual.
} 
273 months $(-0.33 \%$ in months with a credit event and $+0.06 \%$ in other months). As expected, the difference in excess returns is mainly driven by the largest firms: measured by bonds outstanding, these firms' events lead to an average excess corporate bond return of $-1.05 \%$; among firms with the greatest assets, the average drop was $53 \mathrm{bp}$. These negative excess returns often occur with flights to quality or other times when Treasury returns are unusually large. Returns on stocks are unaffected by these credit shocks on average. This would be expected if a large fraction of the credit events stem from leveraged buyouts and other events that are positive news for shareholders.

What if causality runs from Treasuries to corporate bonds in Table 5? If Federal Reserve easing due to a weak economy causes high Treasury returns just at the time when perceived credit risk is increasing, we might see similar market returns. If so, then a large number of credit spread increases (reflecting the weak economy) would randomly result in at least one corporate bond suffering a 200bp spread increase. First, we note this is highly unlikely given that our event months are identified both by a large spread increase and news in the financial press indicating a reason for the jump. However, we can also test this story by investigating the 273 months that are not associated with a credit event to see if highest returns in the Treasury market often cause higher spreads. Specifically, we examine the 25 months with the best Treasury returns and test the excess return for the corporate bond market during those months. We find they actually have significantly positive excess returns on corporates, indicating again that Treasury returns do not cause the observed corporate bond events.

\subsection{Regression Analysis}

The t-tests in Table 5 implicitly assume that only credit shocks affect monthly asset returns, as other factors are ignored. In Table 6 we report regressions that control for other effects, such as macroeconomic factors. In the corporate bond and stock market regressions we also include the slope of the term structure, as Estrella and Hardouvelis (1991) show that it predicts recessions. For the Treasury return regression, we do not include the slope of the Treasury curve as an explanatory variable, as it may cause a spurious relationship in the estimation. To control for the effect of changes in real rates, we also include the current month's change in the actual Federal Funds rate or alternatively the Federal Funds rate relative to inflation (the Taylor rule variable: FF-inflation-2 percent (see Taylor (1993)).

We also include measures of flight to quality (FTQ) in the Treasury market: an indicator variable for instances of FTQ that are not related to the credit events we identify and changes in institutional money market mutual fund flows. Longstaff argues that changes in money fund 
flows are indicative of changes in sentiment that occur with a FTQ. However, money funds were in their infancy at the start of our sample period, leading to very high growth rates that undoubtedly do not reflect such changes in sentiment. Nevertheless, we investigate the effects for comparison sake.

Our indicator variable for the other FTQ episodes is based on information culled from the financial press. For the part of the sample from June 1979 on, we set the indicator to one whenever the Wall Street Journal (WSJ) uses the phrase "flight to quality" to explain why prices of Treasuries have risen in that calendar month. If the WSJ uses the phrase to describe a long term trend (say 3 months) in Treasury prices, we do not count it as FTQ. For the period from 1973 to May 1979, the WSJ index is not available in electronic form and we search for references to FTQ in three sources: (1) the weekly write-up of the bond market in Moody's Bond Survey; ((2) market commentary of Aubrey Lanston (various issues, 19731979), a government bond trading firm; and (3)Lexis-Nexus. Treasury securities" If any of the sources mention FTQ in Treasuries comparable to those used for the WSJ, we set the indicator to one for that month.

We obtain closing VIX implied volatilities from the CBOE website (data begins in 1986). Corporate bond upgrade to downgrade ratios are obtained from Moody's Investors Service, as are monthly default rates. Because the VIX severely limits the time span of analysis, we proxy for the VIX with historical stock return volatility (volatility is calculated using the variance of daily returns on the S\&P 500, including dividends).

The effects of credit events on corporate bonds in Table 6 are similar to those found in the ttests, again with a larger effect occurring when the credit event is associated with bigger firms. (These regressions are corrected for heteroskedasticity and autocorrelation by the Newey-West method using five lags). In the first column of Table 6, which uses an indicator for all credit shocks regardless of firm size, excess corporate returns are significantly lower in credit event months. Meanwhile, the signs of the control variables are largely as expected: a steep yield curve implies a strong economy and thus a lower chance of default, while Fed tightening indicates that the peak in the current business cycle has arrived (with defaults increasing soon). The trade deficit situation is also very significant, which may reflect the fact that the corporate bond market includes more exporters than the economy in general. Defaults and rating changes are not significant, regardless of the lead/lag relationship used in the regression (results not reported).

Several of the macro variables are insignificant, and are dropped for the sake of parsimony in the remaining specifications. Likewise the FTQ indicator is not important for the corporate 
bond market. (In results not reported we also find that using the on the run/off the run spread as a proxy for FTQ is not significant.) This likely reflects the relative safety of bonds in these other episodes that are not related to credit risk in the bond market.

In the next two columns of Table 6 we report regressions of excess bond returns where the credit event months are split into those with large firms and those with small firm shocks (size is measured by firm assets). As in the t-tests, the impact is greatest in months when large firms experience credit shocks. These two columns differ in the treatment of stock return volatility. One includes the VIX volatility measure, which is only available from 1986 . The VIX affects the coefficient on the indicator for the October 1987 crash as well as the default rate and ratio of upgrades to downgrades, but this largely reflects the time period for which the VIX is available. We further consider the role of volatility by replacing the VIX with the monthly standard deviation of daily S\&P 500 returns (including dividends). This variable has no discernible impact on corporate bond returns. We also include institutional money fund flow innovations in the second model, but its coefficient is not significant.

The two middle columns of Table 6 show the results of regressions explaining Treasury returns. The corporate credit shocks have a positive impact on Treasury returns, suggestive of a flight to quality effect. The coefficient on the FTQ indicator implies this phenomenon occurs in many more situations than just credit events. While the credit shock indicator has a coefficient of $54 \mathrm{bp}$, the other instances of FTQ have an average impact of more than $70 \mathrm{bp}$. The October 1987 stock market crash likely has a much larger FTQ impact. The model in the second Treasury specification indicates that credit shocks mainly impact the Treasury market when they involve large firms. ${ }^{36}$

The last two columns of Table 6 shows regressions analyzing the effect of our credit shocks on excess stock returns. Unlike the t-tests, these estimations indicate that CRSP stocks suffer in months with credit events. These regressions control for macroeconomic factors, such as the Federal Funds rate and consumer confidence. For stocks, higher consumer confidence always leads to higher returns. This variable impinges on the significance of the credit events, suggesting that confidence drops when these events occur. In the second specification, large firm credit event months are significantly negative once we drop the consumer confidence variable.

Our results suggest that unexpected credit events lead to significant losses on a corporate bond portfolio. This is consistent with our model's assumption that credit events affect the pricing kernel.

\footnotetext{
${ }^{36}$ In results not reported, the on the run/off the run spread and the money fund variable are not significant.
} 


\section{Conclusion}

Empirical studies find that only a small fraction of investment grade credit spreads can be explained in terms of covariance of bond returns with a proxy for the pricing kernel. Reduced form models of default attribute the large, unexplained residuals as compensation for jump-todefault risk, but do not investigate how these default events covary with their pricing kernel proxy. Moreover, the models tested have precluded the most economically reasonable justification for JTD to be priced, namely, a contagion channel, where the aggregate corporate bond index reacts adversely to a credit event. In this paper, we consider two frameworks: one where JTD risk is priced because of its impact on aggregate corporate bond indices, and one where JTD risk is priced because defaults provide information regarding a hidden macro-economic state. Simple calibrations of our models indicate that JTD premia have an upper bound of a few basis points and that, especially at the long end, contagion premia should dominate JTD premia, and could potentially account for a significant portion of credit spreads. Since the framework proposed is tractable in capturing contagion even among a large number of firms, we suspect the model should also be useful for the pricing of CDO tranches.

We also find empirical evidence for credit contagion by studying the response of corporate bonds, Treasuries and equity indices to 'surprise' credit events incurred by individual firms. These events lead to market-wide increases in credit spreads, and downward jumps in risk-free rates. Furthermore, consistent with intuition, we find that credit events of large firms have a more significant effect on the market than credit events of small firms. The positive impact on Treasury returns of credit events is substantial and seems robust. It is consistent with the notion of 'flight to quality,' and indeed with the predictions of our simple 'fragile beliefs' equilibrium model. 


\section{References}

[1] C. M. Ahn and H. E. Thomson. Jump diffusion processes and the term structure of interest rates. Journal of Finance, 1:155-175, 1988.

[2] K. Bae, G. A. Karolyi, and R. M. Stulz. A new approach to measuring financial contagion. The Review of Financial Studies, 16:717-763, 2003.

[3] R. Bansal and A. Yaron. Risks for the long run: A potential resolution of asset pricing puzzles. Journal of Finance, 59:1481-1509, 2004.

[4] A. Berndt, R. Douglas, D. Duffie, M. Ferguson, and D. Schranz. Measuring default risk premia from default swap rates and edfs. BIS Working Paper no. 173, 2005.

[5] J. Y. Campbell and J. Cochrane. By force of habits: A consumption based explanation of aggregate stock market returns. Journal of Political Economy, 107:205-251, 1999.

[6] L. Chen, P. Collin-Dufresne, and R. Goldstein. On the relation between the credit spread puzzle and the equity premium puzzle. The Review of Financial Studies, 22:3367-3409, 2009 .

[7] P. Collin-Dufresne and R. Goldstein. Dynamic consistency and fragile beliefs. Working Paper, Columbia University, 2009.

[8] P. Collin-Dufresne, R. Goldstein, and J. Hugonnier. A general formula for valuing defaultable securities. 72:1377-1407, 2004.

[9] P. Collin-Dufresne, R. S. Goldstein, and J. S. Martin. The determinants of credit spread changes. Journal of Finance, 56:2177-2208, 2001.

[10] J. C. Cox, J. E. Ingersoll Jr., and S. A. Ross. An intertemporal general equilibrium model of asset prices. Econometrica, 53:363-384, 1985a.

[11] L. Crabbe. Event risk: An analysis of losses to bondholders and "super poison put" bond covenants. Journal of Finance, pages 689-706, 1991.

[12] S. Das, D. Duffie, N. Kapadia, and L. Saita. Common failings: How corporate defaults are correlated. Journal of Finance, 62:93-117, 2007.

[13] S. Das, L. Freed, N. Kapadia, and G. Geng. Correlated default risk. Journal of Fixed Income, 16:7-32, 2006. 
[14] A. David. Fluctuating confidence in stock markets:implications for returns and volatility. Journal of Financial and Quantitative Analysis, 32:427-462, 1997.

[15] M. Davis and V. Lo. Infectious defaults. 1:382-387, 2001.

[16] J. Detemple. Asset pricing in a production economy with incomplete information. Journal of Finance, 41:383-393, 1986.

[17] J. Driessen. Is default event risk priced in corporate bonds. The Review of Financial Studies, 18:165-195, 2005.

[18] G. R. Duffee. Estimating the price of default risk. The Review of Financial Studies, 12:187-226, 1999.

[19] D. Duffie and R. Kan. A yield-factor model of interest rates. Mathematical Finance, 6:379-406, 1996.

[20] D. Duffie and D. Lando. Term structure of credit spreads with incomplete accounting information. Econometrica, 69:633-664., 2001.

[21] D. Duffie, M. Schroder, and C. Skiadas. Recursive valuation of defaultable securities and the timing of resolution of uncertainty. The Annals of Applied Probability, 6:1075-1090, 1996.

[22] D. Duffie and K. Singleton. An econometric model of the term structure of interest-rate swap yields. Journal of Finance, LII.no.4:1287-1381, 1997.

[23] D. Duffie and K. Singleton. Modeling term structures of defaultable bonds. The Review of Financial Studies, 12 nb. 4:687-720, 1999.

[24] E. J. Elton, M. J. Gruber, D. Agrawal, and C. Mann. Explaining the rate spread on corporate bonds. Journal of Finance, 56 no. 1:247-277, 2001.

[25] Y. H. Eom, J. Helwege, and J.-Z. Huang. Structural models of corporate bond pricing: An empirical analysis. The Review of Financial Studies, 17:499-544, 2004.

[26] A. Estrella and G. Hardouvelis. The term structure as a predictor of real economic activity. Journal of Finance, 46:555-576, 1991.

[27] D. Feldman. The term structure of interest rates in a partially observable economy. Journal of Finance, VOL 44:789-812, 1989. 
[28] M. Fleming and E. Remolona. Price formation and liquidity in the us treasury market: The response to public information. Journal of Finance, 54:31-50, 1999.

[29] K. Giesecke. Correlated default with incomplete information. Journal of Banking and Finance, 28:1521-1545, 2004.

[30] S. Gilchrist, V. Yankov, and E. Zakrajsek. Credit market shocks and economic fluctuations: Evidence from corporate bond and stock markets. Journal of Monetary Economics, 56:471-493, 2009.

[31] L. P. Hansen. Beliefs, doubts and learning: Valuing macroeconomic risk. The American Economic Review, 97:1-30, 2007.

[32] L. P. Hansen and T. J. Sargent. Fragile beliefs and the price of uncertainty. Working Paper, University of Chicago, 2009.

[33] J. Huang and M. Huang. How much of the corporate-treasury yield spread is due to credit risk? a new calibration approach. Working paper Stanford University, 2003.

[34] R. Jarrow, D. Lando, and F. Yu. Default risk and diversification: Theory and empirical implications. Mathematical Finance, v15n1:1-26, 2005.

[35] R. Jarrow and F. Yu. Counterparty risk and the pricing of defaultable securities. Journal of Finance, v56n5:1765-99, 2001.

[36] R. A. Jarrow, D. Lando, and S. Turnbull. A markov model for the term structure of credit spreads. The Review of Financial Studies, 10:481-523, 1997.

[37] P. E. Jones, S. P. Mason, and E. Rosenfeld. Contingent claims analysis of corporate capital structures: An empirical investigation. Journal of Finance, v39 n3 July:611-25, 1984.

[38] P. Jorion and G. Zhang. Good and bad credit contagion: Evidence from credit default swaps. Journal of Financial Economics, 84:860-883, 2007.

[39] P. Jorion and G. Zhang. Credit contagion and counterparty risk. Journal of Finance, 64:2053-2087, 2009.

[40] M. A. King and S. Wadhwani. Transmission of volatility between stock markets. The Review of Financial Studies, VOL 3:5-33, 1990. 
[41] L. E. Kodres and M. Pritsker. A rational expectations model of financial contagion. Journal of Finance, VOL LVII NO 2:769-799, 2002.

[42] D. Lando. On cox processes and credit risky securities. The Review of Derivatives Research, 2:99-120, 1998.

[43] D. Lando and M. Nielsen. Correlation in corporate defaults: Contagion or conditional independence? Working Paper, Copenhagen Business School, 2009.

[44] L. Lang and R. Stulz. Contagion and competitive intra-industry effects of bankruptcy announcements. Journal of Financial Economics, 32:45-60, 1992.

[45] M. Lettau and S. Ludvigson. Consumption, aggregate wealth, and expected stock returns. Journal of Finance, 56:815-849, 2001.

[46] R. Lipster and A. Shiryaev. Statistics of Random Processes II: Volume 2- Applications. 2000 .

[47] F. Longstaff. The flight to liquidity in US Treasury bond prices. JB, 77:511-526, 2004.

[48] D. Madan and H. Unal. Pricing the risks of default. The Review of Derivatives Research, v2, n2-3:121-60, 1998.

[49] R. C. Merton. On the pricing of corporate debt: The risk structure of interest rates. Journal of Finance, 29:449-470, 1974.

[50] C. Nelson and A. Siegel. Parsimonious modeling of yield curves. Journal of Business, 60:473-489, 1987.

[51] P. J. Schönbucher and D. Schubert. Copula-dependent default risk in intensity models. Working Paper, Bonn University, 2001.

[52] J. Taylor. Discretion versus policy rules in practice. Carnegie-Rochester Conference Series on Public Policy, 39:195-214, 1993.

[53] G. Theocharides. Contagion: Evidence from the bond market. Working Paper, Sungkyunkwan University, 2007.

[54] P. Veronesi. How does information quality affect stock returns. Journal of Finance, VOL LV NO 2:807-837, 2000.

[55] A. Warga and I. Welch. bondholder losses in leveraged buyouts. RFS, 6:959-982, 1993. 
[56] A. D. Warga. Corporate bond price discrepancies in the dealer and exchange markets. Journal of Fixed Income, 1:7-16, 1991.

[57] F. Yu. Accounting transparency and the term structure of credit spreads. Journal of Financial Economics, 75:53-84, 2005.

[58] C. Zhou. The term structure of credit spreads with jump risk. Journal of Banking and Finance, v25n11:2015-40, 2001. 


\section{Appendix}

\subsection{Technical appendix for the survival probability}

$$
\begin{aligned}
\mathrm{E}_{0}^{Q}\left[\mathbf{1}_{\{\tau>T\}}\right] & \equiv \pi_{0}^{Q}[\tau>T]=e^{-\lambda_{0}^{Q} T} \\
\mathrm{E}_{0}^{Q}\left[\mathbf{1}_{\{\tau \in(t, t+d t)\}}\right] & \equiv \pi_{0}^{Q}[\tau=t] d t=e^{-\lambda_{0}^{Q} t} \lambda_{0}^{Q} d t \\
\mathrm{E}^{Q}\left[e^{-\int_{0}^{T} d s \lambda^{Q}(s)} \mid \tau=t\right] & \equiv \mathrm{E}^{Q}\left[e^{-\int_{0}^{t} d s \lambda^{Q}(s)} \mid \tau=t\right] \mathrm{E}^{Q}\left[e^{-\int_{t}^{T} d s \lambda^{Q}(s)} \mid \tau=t\right] \\
& =e^{-\lambda_{0}^{Q} t} e^{-\left(\lambda_{0}^{Q}+\alpha\right)(T-t)},
\end{aligned}
$$

we find

$$
\begin{aligned}
\mathrm{E}_{0}^{Q}\left[e^{-\int_{0}^{T} d s \lambda^{Q}(s)}\right] & =\pi_{0}^{Q}[\tau>T] \mathrm{E}_{0}^{Q}\left[e^{-\int_{0}^{T} d s \lambda^{Q}(s)} \mid \tau>T\right]+\int_{0}^{T} d t \pi_{0}^{Q}[\tau=t] \mathrm{E}_{0}^{Q}\left[e^{-\int_{0}^{T} d s \lambda^{Q}(s)} \mid \tau=t\right] \\
& =\left(e^{-\lambda_{0}^{Q} T}\right)\left(e^{-\lambda_{0}^{Q} T}\right)+\int_{0}^{T}\left(d t e^{-\lambda_{0}^{Q} t} \lambda_{0}^{Q}\right)\left(e^{-\lambda_{0}^{Q} t} e^{-\left(\lambda_{0}^{Q}+\alpha\right)(T-t)}\right) \\
& =e^{-2 \lambda_{0}^{Q} T}+\left(\frac{\lambda_{0}^{Q}}{\lambda_{0}^{Q}-\alpha}\right) e^{-\left(\lambda_{0}^{Q}+\alpha\right) T}\left[1-e^{-\left(\lambda_{0}^{Q}-\alpha\right) T}\right] .
\end{aligned}
$$

\subsection{Technical appendix for the updating equation}

Here we provide a heuristic derivation for the updating equation (38). ${ }^{37}$ Since defaults are triggered by point processes, investors observe, at most, one event per unit time. Define $\left.d \mathbf{1}_{t} \equiv d \mathbf{1}_{\left\{\tau_{i}<t\right\}}\right|_{i=1} ^{N}$ as the vector of jump events. Consider first the case where no default is observed in a period $d t$. Using the definition of conditional probability, and keeping terms only to $\mathcal{O}(d t)$, we obtain:

$$
\begin{aligned}
& \operatorname{Pr}\left[\tilde{S}=s, d \mathbf{1}_{t}=0 \mid \mathcal{F}_{t}\right]=\operatorname{Pr}\left[d \mathbf{1}_{t}=0 \mid \tilde{S}=s, \mathcal{F}_{t}\right] \times \operatorname{Pr}\left[\tilde{S}=s \mid \mathcal{F}_{t}\right] \\
&=\prod_{i=1}^{N}\left(1-\lambda_{i s}\left(t^{-}\right) \mathbf{1}_{\left\{\tau_{i}>t\right\}} d t\right) \times \pi_{s}(t) \\
& \stackrel{\mathcal{O}(d t)}{=} \\
& \pi_{s}(t)\left(1-\sum_{i=1}^{N} \lambda_{i s}\left(t^{-}\right) \mathbf{1}_{\left\{\tau_{i}>t\right\}} d t\right) .
\end{aligned}
$$

Again using conditional expectations, we find that the process for $\pi_{s}(t)$, conditional upon no firm defaulting during the interval $(t, t+d t)$, evolves via

$$
\left.\pi_{s}(t+d t)\right|_{\left(d \mathbf{1}_{t}=0\right)} \equiv \operatorname{Pr}\left[\tilde{S}=s \mid d \mathbf{1}_{t}=0, \mathcal{F}_{t}\right]
$$

\footnotetext{
${ }^{37}$ More rigorously, the result is a direct application of theorem 19.6 page 332 in Lipster and Shiryaev (see also their example 1 p. 333)
} 


$$
\begin{aligned}
& =\frac{\operatorname{Pr}\left[\tilde{S}=s, d \mathbf{1}_{t}=0 \mid \mathcal{F}_{t}\right]}{\operatorname{Pr}\left[d \mathbf{1}_{t}=0 \mid \mathcal{F}_{t}\right]} \\
& =\frac{\operatorname{Pr}\left[\tilde{S}=s, d \mathbf{1}_{t}=0 \mid \mathcal{F}_{t}\right]}{\sum_{s^{\prime}=1}^{M} \operatorname{Pr}\left[\tilde{S}=s^{\prime}, d \mathbf{1}_{t}=0 \mid \mathcal{F}_{t}\right]} \\
& =\frac{\pi_{s}(t)\left(1-\sum_{i=1}^{N} \lambda_{i s}\left(t^{-}\right) \mathbf{1}_{\left\{\tau_{i}>t\right\}} d t\right)}{\sum_{s^{\prime}=1}^{M} \pi_{s^{\prime}}(t)\left(1-\sum_{i=1}^{N} \lambda_{i s^{\prime}}\left(t^{-}\right) \mathbf{1}_{\left\{\tau_{i}>t\right\}} d t\right)} \\
& =\frac{\pi_{s}(t)\left(1-\sum_{i=1}^{N} \lambda_{i s}\left(t^{-}\right) \mathbf{1}_{\left\{\tau_{i}>t\right\}} d t\right)}{1-\sum_{i=1}^{N} \bar{\lambda}_{i}\left(t^{-}\right) \mathbf{1}_{\left\{\tau_{i}>t\right\}} d t} \\
& \underline{\underline{\mathcal{O}(d t)}}=\pi_{s}(t)\left[1-\sum_{i=1}^{N}\left(\lambda_{i s}\left(t^{-}\right)-\bar{\lambda}_{i}\left(t^{-}\right)\right) \mathbf{1}_{\left\{\tau_{i}>t\right\}} d t\right],
\end{aligned}
$$

where we have used equation (37) and the fact that $\sum_{s^{\prime}=1}^{M} \pi_{s^{\prime}}(t)=1$ in the second-to-last line. Hence, if there are no jumps during the interval $d t$, then the Bayesian updating follows the process:

$$
\left.d \pi_{s}(t)\right|_{\left(d \mathbf{1}_{t}=0\right)}=-\pi_{s}(t) \sum_{i=1}^{N}\left(\lambda_{i s}\left(t^{-}\right)-\bar{\lambda}_{i}\left(t^{-}\right)\right) \mathbf{1}_{\left\{\tau_{i}>t\right\}} d t .
$$

In contrast, if one firm (e.g., firm i) defaults during the interval $d t$, then, for all states- $j$, we obtain the updating:

$$
\begin{aligned}
\operatorname{Pr}\left[\tilde{S}=s, d \mathbf{1}_{\left\{\tau_{i}<t\right\}}=1 \mid \mathcal{F}_{t}\right] & \equiv \operatorname{Pr}\left[d \mathbf{1}_{\left\{\tau_{i}<t\right\}}=1 \mid \tilde{S}=s, \mathcal{F}_{t}\right] \times \operatorname{Pr}\left[\tilde{S}=s \mid \mathcal{F}_{t}\right] \\
& =\pi_{s}(t) \lambda_{i s}\left(t^{-}\right) d t .
\end{aligned}
$$

Hence, it follows that, conditional on firm- $i$ defaulting during the interval $(t, t+d t)$, the process for $\pi_{s}(t)$ evolves via

$$
\begin{aligned}
\left.\pi_{s}(t+d t)\right|_{\left(d \mathbf{1}_{\left\{\tau_{i}<t\right\}}=1\right)} & =\operatorname{Pr}\left[\tilde{S}=s \mid d \mathbf{1}_{\left\{\tau_{i}<t\right\}}=1, \mathcal{F}_{t}\right] \\
& =\frac{\operatorname{Pr}\left[\tilde{S}=s, d \mathbf{1}_{\left\{\tau_{i}<t\right\}}=1 \mid \mathcal{F}_{t}\right]}{\operatorname{Pr}\left[d \mathbf{1}_{\left\{\tau_{i}<t\right\}}=1 \mid \mathcal{F}_{t}\right]} \\
& =\frac{\operatorname{Pr}\left[\tilde{S}=s, d \mathbf{1}_{\left\{\tau_{i}<t\right\}}=1 \mid \mathcal{F}_{t}\right]}{\sum_{s^{\prime}=1}^{M} \operatorname{Pr}\left[\tilde{S}=s^{\prime}, d \mathbf{1}_{\left\{\tau_{i}<t\right\}}=1 \mid \mathcal{F}_{t}\right]} \\
& =\frac{\pi_{s}(t) \lambda_{i s}\left(t^{-}\right)}{\bar{\lambda}_{i}\left(t^{-}\right)}
\end{aligned}
$$


where we have used equations (37) and (83) in the last line. Therefore, we can write

$$
\left.d \pi_{s}(t)\right|_{\left(d \mathbf{1}_{\left\{\tau_{i}<t\right\}}=1\right)}=\pi_{s}(t)\left(\frac{\lambda_{i s}\left(t^{-}\right)}{\bar{\lambda}_{i}\left(t^{-}\right)}-1\right) d \mathbf{1}_{\left\{\tau_{i}<t\right\}} .
$$

Combining equations (82) and (85) we obtain the updating process for $\pi_{s}(t)$ :

$$
d \pi_{s}(t)=\pi_{s}(t) \sum_{i=1}^{N}\left[\left(\frac{\lambda_{i s}\left(t^{-}\right)}{\bar{\lambda}_{i}\left(t^{-}\right)}-1\right)\left(d \mathbf{1}_{\left\{\tau_{i} \leq t\right\}}-\bar{\lambda}_{i}\left(t^{-}\right) \mathbf{1}_{\left\{\tau_{i}>t\right\}} d t\right)\right]
$$

\subsection{The no-jump condition}

For simplicity, and since a counter-example suffices, we consider the case where the intensity is constant conditional on a state. If the no-jump condition held then we would have the following equality:

$$
\mathrm{E}\left[\mathbf{1}_{\{\tau>T\}}\right]=\mathbf{1}_{\{\tau>t\}} \mathrm{E}_{t}\left[e^{-\int_{t}^{T} \bar{\lambda}^{P}(u) d u}\right]
$$

where $\bar{\lambda}(t)=\sum_{s} \pi_{s}(t) \lambda^{s}$. On the other hand we have shown (using the Bayes rule) that:

$$
\mathrm{E}\left[\mathbf{1}_{\{\tau>T\}}\right]=\mathbf{1}_{\{\tau>t\}} \sum_{s} \pi_{s}(t) e^{-\lambda^{s}(T-t)}
$$

So if the no-jump condition rule works then we should have:

$$
\mathrm{E}_{t}\left[e^{-\int_{t}^{T} \bar{\lambda}^{P}(u) d u}\right]=\sum_{s} \pi_{s}(t) e^{-\lambda^{s}(T-t)}
$$

In particular, the process $M(t)$ defined below should be a martingale:

$$
M(t)=e^{-\int_{0}^{t} \bar{\lambda}^{P}(u) d u} \sum_{s} \pi_{s}(t) e^{-\lambda^{s}(T-t)}
$$

But

$$
d M(t)=e^{-\int_{0}^{t} \bar{\lambda}^{P}(u) d u} \sum_{s} \pi_{s}(t) e^{-\lambda^{s}(T-t)}\left\{\lambda^{s}-\bar{\lambda}^{P}(t)+\frac{d \pi_{s}(t)}{\pi_{s}(t)}\right\} d t
$$

So clearly $\mathrm{E}[d M(t)] \neq 0$.

\subsection{Proof of the bond price formula}

Using the definition of the 'conditional' pricing kernel write the expectation

$$
\mathrm{E}_{t}\left[\frac{\Lambda^{s}(T)}{\Lambda^{s}(t)} e^{\left.-\int_{t}^{T} \lambda_{i s}(u) d u\right)} \mid S_{t}=\mathbf{1}_{s}\right]=e^{-r^{s}(T-t)} \tilde{\mathrm{E}}_{t}\left[e^{-\int_{t}^{T} \lambda_{i s}(u) d u}\right]
$$

where under the $\tilde{P}$ measure the dynamics of $x_{i}(t)$ is:

$$
d \lambda_{i s}(t)=\kappa_{i}\left(\theta_{i s}-\lambda_{i s}(t)\right) d t+v_{i s} \sqrt{\lambda_{i s}(t)} d Z_{i}(t)
$$


We want to show that:

$$
\tilde{\mathrm{E}}_{t}\left[e^{-\int_{t}^{T} \lambda_{i s}(u) d u}\right]=e^{\mathcal{A}(T-t)-\mathcal{B}(T-t) \lambda_{i s}(t)}
$$

To that effect it is sufficient to find functions $\mathcal{A}(\tau), \mathcal{B}(\tau)$ such that the process $M(\lambda(t), t)=$ $e^{-\int_{0}^{t} \lambda(u) d u} e^{\mathcal{A}(T-t)-\mathcal{B}(T-t) \lambda(t)}$ is a $\tilde{P}$ martingale. Applying the Itô-Doeblin rule to $M(\lambda(t), t)$ and setting the drift to zero we obtain the system of ODE to be solved by the functions.

$$
\begin{gathered}
\tilde{\mathrm{E}}\left[\frac{d M(\lambda(t), t)}{M(\lambda(t), t)}\right]=-A^{\prime}+B^{\prime} \lambda-B \kappa(\theta-\lambda)+\frac{1}{2} B^{2} v^{2} \lambda-\lambda=0 \\
A^{\prime}=-B \kappa \theta \\
-B^{\prime}=B \kappa+\frac{1}{2} B^{2} v^{2}-1
\end{gathered}
$$

The boundary conditions are $A(0)=B(0)=0$. We recognize the standard CIR formulae. 


\section{Tables}

\begin{tabular}{rcccc}
\hline$\gamma$ & $\Gamma_{C}^{\text {implied }}$ & $(\mu-r)_{C}$ & $(\mu-r)_{J}$ & $\left(\frac{\lambda^{Q}}{\lambda^{P}}\right)$ \\
\hline 5 & 0.033 & 122.8 & 2.2 & 1.19 \\
10 & 0.023 & 121.8 & 3.2 & 1.27 \\
15 & 0.018 & 121.0 & 4.0 & 1.33 \\
20 & 0.016 & 120.4 & 4.6 & 1.39 \\
\hline
\end{tabular}

Table 1: We decompose 125bp of excess return into that due to jump-to-default risk and that due to contagion risk for select values of the constant relative risk aversion coefficient $\gamma$. Parameter values are $\Gamma_{D}=0.6$, $\lambda^{P}=0.002$ and $N=1000$.

\begin{tabular}{rcccc}
\hline$\gamma$ & $\Gamma_{C}^{\text {implied }}$ & $(\mu-r)_{C}$ & $(\mu-r)_{J}$ & $\left(\frac{\lambda^{Q}}{\lambda^{P}}\right)$ \\
\hline 5 & 0.022 & 53.5 & 1.5 & 1.12 \\
10 & 0.015 & 52.9 & 2.1 & 1.17 \\
15 & 0.012 & 52.4 & 3.6 & 1.21 \\
20 & 0.010 & 52.0 & 3.0 & 1.25 \\
\hline
\end{tabular}

Table 2: We decompose 55bp of excess return into that due to jump-to-default risk and that due to contagion risk for select values of the constant relative risk aversion coefficient $\gamma$. Parameter values are $\Gamma_{D}=0.6$, $\lambda^{P}=0.002$ and $N=1000$.

\begin{tabular}{rcccc}
\hline$\gamma$ & $\Gamma_{C}^{\text {implied }}$ & $(\mu-r)_{C}$ & $(\mu-r)_{J}$ & $\left(\frac{\lambda^{Q}}{\lambda^{P}}\right)$ \\
\hline 5 & 0.034 & 124.6 & 0.4 & 1.19 \\
10 & 0.023 & 124.4 & 0.5 & 1.27 \\
15 & 0.019 & 124.3 & 0.7 & 1.33 \\
20 & 0.016 & 122.2 & 0.8 & 1.39 \\
\hline
\end{tabular}

Table 3: We decompose 125bp of excess return into that due to jump in spread risk and that due to contagion risk for select values of the constant relative risk aversion coefficient $\gamma$. Parameter values are $\Gamma_{D}=0.10$, $\lambda^{P}=0.002$ and $N=1000$. 


\begin{tabular}{|l|rrrrr|}
\hline & $\begin{array}{r}\text { Number of } \\
\text { observations }\end{array}$ & Percentage & $\begin{array}{r}\text { Average } \\
\text { Return }\end{array}$ & $\begin{array}{r}\text { Excess } \\
\text { Return }\end{array}$ & $\begin{array}{r}\text { Average } \\
\text { Duration }\end{array}$ \\
\hline \hline Over 10 percentage points & 7 & $0.01 \%$ & $-31.33 \%$ & $-31.37 \%$ & $2.36 \%$ \\
5 to 10 percentage points & 6 & $0.01 \%$ & $-17.43 \%$ & $-16.79 \%$ & $3.17 \%$ \\
3 to 5 percentage points & 32 & $0.06 \%$ & $-12.40 \%$ & $-12.91 \%$ & $4.26 \%$ \\
2 to 3 percentage points & 113 & $0.21 \%$ & $-7.74 \%$ & $-8.93 \%$ & $4.57 \%$ \\
1.5 to 2 percentage points & 146 & $0.28 \%$ & $-5.42 \%$ & $-6.69 \%$ & $4.76 \%$ \\
1.25 to 1.5 percentage points & 131 & $0.25 \%$ & $-4.08 \%$ & $-5.50 \%$ & $5.10 \%$ \\
1 to 1.25 percentage points & 273 & $0.52 \%$ & $-2.85 \%$ & $-4.08 \%$ & $4.87 \%$ \\
0.75 to 1 percentage points & 572 & $1.08 \%$ & $-2.00 \%$ & $-3.63 \%$ & $5.70 \%$ \\
0.5 to 0.75 percentage points & 1919 & $3.63 \%$ & $-1.08 \%$ & $-2.84 \%$ & $6.30 \%$ \\
0.25 to 0.5 percentage points & 5776 & $10.93 \%$ & $-0.54 \%$ & $-1.18 \%$ & $6.39 \%$ \\
Less than 0.25 percentage points & 43853 & $83.01 \%$ & $0.08 \%$ & $-0.23 \%$ & $7.71 \%$ \\
\hline
\end{tabular}

Table 4: Distribution of Spread Increases

\begin{tabular}{|c|c|c|c|c|c|}
\hline & \multirow[b]{2}{*}{$\begin{array}{c}\text { All } \\
\text { Events }\end{array}$} & \multicolumn{2}{|c|}{$\begin{array}{c}\text { Size measured } \\
\text { by bonds outstanding }\end{array}$} & \multicolumn{2}{|c|}{$\begin{array}{l}\text { Size measured } \\
\text { by total assets }\end{array}$} \\
\hline & & $\begin{array}{c}\text { Events } \\
\text { Involving } \\
\text { Large Issuers }\end{array}$ & $\begin{array}{c}\text { Events } \\
\text { Involving } \\
\text { Small Issuers }\end{array}$ & $\begin{array}{c}\text { Events } \\
\text { Involving } \\
\text { Large Issuers }\end{array}$ & $\begin{array}{c}\text { Events } \\
\text { Involving } \\
\text { Small Issuers }\end{array}$ \\
\hline Number of events & 25 & 11 & 14 & 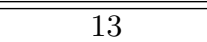 & $\overline{12}$ \\
\hline $\begin{array}{l}\text { Corporate Bond Returns: } \\
\text { in months with events } \\
\text { in months with no events } \\
\text { Difference in returns } \\
\text { T-statistic } \\
\text { p-value }\end{array}$ & $\begin{array}{c}-0.33 \\
0.06 \\
0.39 \\
1.74 \\
0.084\end{array}$ & $\begin{array}{c}-1.05 \\
0.07 \\
1.12 \\
3.42 \\
0.001\end{array}$ & $\begin{array}{c}0.24 \\
0.02 \\
-0.22 \\
-1.50 \\
0.149\end{array}$ & $\begin{array}{c}-0.53 \\
0.06 \\
0.58 \\
1.91 \\
0.057\end{array}$ & $\begin{array}{c}-0.11 \\
0.04 \\
0.15 \\
0.47 \\
0.641\end{array}$ \\
\hline $\begin{array}{l}\text { Treasury Bond Returns: } \\
\text { in months with events } \\
\text { in months with no event } \\
\text { Difference in returns } \\
\text { T-statistic } \\
\text { p-value }\end{array}$ & $\begin{array}{l}1.28 \\
0.70 \\
-0.59 \\
-1.70 \\
0.090\end{array}$ & $\begin{array}{r}1.22 \\
0.73 \\
-0.49 \\
-0.96 \\
0.336\end{array}$ & $\begin{array}{l}1.33 \\
0.72 \\
-0.62 \\
-1.37 \\
0.173\end{array}$ & $\begin{array}{r}1.55 \\
0.71 \\
-0.84 \\
-3.05 \\
0.008\end{array}$ & $\begin{array}{c}0.30 \\
0.76 \\
0.46 \\
0.72 \\
0.471\end{array}$ \\
\hline $\begin{array}{l}\text { Stock Market Returns: } \\
\text { in months with events } \\
\text { in months with no event } \\
\text { Difference in returns } \\
\text { T-statistic } \\
\text { p-value }\end{array}$ & $\begin{array}{c}0.80 \\
1.13 \\
0.33 \\
0.36 \\
0.721\end{array}$ & $\begin{array}{c}0.05 \\
1.14 \\
-1.09 \\
0.57 \\
0.578\end{array}$ & $\begin{array}{c}1.38 \\
1.09 \\
-0.30 \\
-0.25 \\
0.807\end{array}$ & $\begin{array}{c}0.24 \\
1.14 \\
0.90 \\
0.72 \\
0.474\end{array}$ & $\begin{array}{r}1.40 \\
1.09 \\
-0.31 \\
-0.24 \\
0.811\end{array}$ \\
\hline
\end{tabular}

Table 5: Mean Excess Returns of Corporate Bond, Treasury and Stock Indices When Credit Events Occur 


\begin{tabular}{|c|c|c|c|c|c|c|c|}
\hline & \multicolumn{3}{|c|}{$\begin{array}{l}\text { Corporate Bond } \\
\text { Excess Returns }\end{array}$} & \multicolumn{2}{|c|}{$\begin{array}{c}\text { Treasury } \\
\text { Bond Returns }\end{array}$} & \multicolumn{2}{|c|}{$\begin{array}{c}\text { Stock Market } \\
\text { Excess Returns }\end{array}$} \\
\hline & (1) & $(2)$ & $(3)$ & (1) & $(2)$ & (1) & $(2)$ \\
\hline Constant & $\begin{array}{r}-0.22 \\
(-1.88)\end{array}$ & $\begin{array}{r}0.10 \\
(1.64)\end{array}$ & $\begin{array}{r}-0.09 \\
(-0.84)\end{array}$ & $\begin{array}{r}1.19 \\
(5.20)\end{array}$ & $\begin{array}{r}1.19 \\
(5.18)\end{array}$ & $\begin{array}{r}-1.09 \\
(-4.28)\end{array}$ & $\begin{array}{r}-0.95 \\
(-3.66)\end{array}$ \\
\hline Credit event month & $\begin{array}{r}-0.43 \\
(-2.14)\end{array}$ & - & - & $\begin{array}{r}0.54 \\
(1.72)\end{array}$ & - & $\begin{array}{r}-0.52 \\
(-1.61)\end{array}$ & - \\
\hline Large firm credit event month & - & $\begin{array}{r}-0.39 \\
(-2.67)\end{array}$ & $\begin{array}{r}-0.77 \\
(-3.23)\end{array}$ & - & $\begin{array}{r}0.67 \\
(2.08)\end{array}$ & - & $\begin{array}{r}-0.79 \\
(-2.52)\end{array}$ \\
\hline Small firm credit event month & - & $\begin{array}{r}-0.03 \\
(-0.38)\end{array}$ & $\begin{array}{r}-0.20 \\
(-0.80)\end{array}$ & - & $\begin{array}{r}0.42 \\
(0.78)\end{array}$ & - & $\begin{array}{r}-0.50 \\
(-0.92)\end{array}$ \\
\hline Change in Fed Funds & $\begin{array}{r}-0.22 \\
(-1.63)\end{array}$ & - & - & $\begin{array}{r}-0.32 \\
(-1.64)\end{array}$ & $\begin{array}{r}-0.32 \\
(-1.64)\end{array}$ & $\begin{array}{r}0.29 \\
(1.37)\end{array}$ & $\begin{array}{r}0.37 \\
(1.79)\end{array}$ \\
\hline Change in CPI & - & $\begin{array}{l}- \\
-\end{array}$ & $\begin{array}{l}- \\
-\end{array}$ & $\begin{array}{r}-1.14 \\
(-2.75)\end{array}$ & $\begin{array}{r}-1.15 \\
(-2.75)\end{array}$ & $\begin{array}{r}1.02 \\
(2.21)\end{array}$ & $\begin{array}{r}0.67 \\
(0.48)\end{array}$ \\
\hline Change in Taylor rule & - & $\begin{array}{r}0.07 \\
(0.54)\end{array}$ & $\begin{array}{r}-0.27 \\
(-2.30)\end{array}$ & - & - & & - \\
\hline Change in defaults & $\begin{array}{r}14.45 \\
(0.90)\end{array}$ & $\begin{array}{l}-14.95 \\
(-2.04)\end{array}$ & $\begin{array}{r}16.16 \\
(1.01)\end{array}$ & - & - & - & - \\
\hline Change in upgrade/downgrade ratio & $\begin{array}{r}0.02 \\
(0.07)\end{array}$ & $\begin{array}{r}0.08 \\
(1.62)\end{array}$ & $\begin{array}{r}0.04 \\
(0.13)\end{array}$ & - & - & - & - \\
\hline Slope of the yield curve & $\begin{array}{r}0.35 \\
(3.26)\end{array}$ & $\begin{array}{r}0.008 \\
(0.17)\end{array}$ & $\begin{array}{r}0.35 \\
(3.28)\end{array}$ & - & - & $\begin{array}{r}-0.07 \\
(-0.58)\end{array}$ & $\begin{array}{r}-0.06 \\
(-0.45)\end{array}$ \\
\hline Change in consumer confidence & $\begin{array}{r}-0.79 \\
(-0.80)\end{array}$ & - & - & $\begin{array}{r}-4.94 \\
(-2.63)\end{array}$ & $\begin{array}{r}-4.93 \\
(-2.61)\end{array}$ & $\begin{array}{r}5.01 \\
(2.66)\end{array}$ & - \\
\hline Change in current account & $\begin{array}{r}0.17 \\
(2.93)\end{array}$ & $\begin{array}{r}0.06 \\
(1.54)\end{array}$ & $\begin{array}{r}0.17 \\
(2.76)\end{array}$ & $\begin{array}{r}0.12 \\
(1.25)\end{array}$ & $\begin{array}{r}0.12 \\
(1.16)\end{array}$ & $\begin{array}{r}-0.13 \\
(-1.28)\end{array}$ & $\begin{array}{r}-0.19 \\
(-1.68)\end{array}$ \\
\hline Change in payrolls & $\begin{array}{r}0.0003 \\
(0.77)\end{array}$ & - & - & $\begin{array}{r}-0.001 \\
(1.33)\end{array}$ & $\begin{array}{l}-0.001 \\
(-1.27)\end{array}$ & $\begin{array}{r}0.001 \\
(1.34)\end{array}$ & $\begin{array}{r}0.001 \\
(1.22)\end{array}$ \\
\hline Change in IP & $\begin{array}{l}-0.0006 \\
(-0.006)\end{array}$ & - & - & - & - & - & - \\
\hline Indicator for 1987 crash & $\begin{array}{r}-1.32 \\
(-5.73)\end{array}$ & $\begin{array}{r}0.80 \\
(1.15)\end{array}$ & $\begin{array}{r}-0.59 \\
(-0.85)\end{array}$ & $\begin{array}{r}2.82 \\
(8.37)\end{array}$ & $\begin{array}{r}2.81 \\
(8.32)\end{array}$ & $\begin{array}{r}-3.03 \\
(-9.24)\end{array}$ & $\begin{array}{r}-3.04 \\
(-8.70)\end{array}$ \\
\hline Flight to quality indicator & $\begin{array}{r}0.28 \\
(1.55)\end{array}$ & - & - & $\begin{array}{r}0.72 \\
(2.43)\end{array}$ & $\begin{array}{r}0.72 \\
(2.43)\end{array}$ & $\begin{array}{r}-0.70 \\
(-2.35)\end{array}$ & $\begin{array}{r}-0.75 \\
(-2.45)\end{array}$ \\
\hline Shock to institutional money funds & - & $\begin{array}{r}-.02 \\
(-.22)\end{array}$ & - & & & & - \\
\hline Change in VIX (post 1986) & - & $\begin{array}{l}-0.047 \\
(-2.52)\end{array}$ & - & - & - & - & - \\
\hline Stock return volatility & - & - & $\begin{array}{r}-9.14 \\
(-0.66)\end{array}$ & - & - & - & - \\
\hline Adjusted $\mathrm{R}^{2}$ & 0.12 & 0.13 & 0.13 & 0.16 & 0.16 & 0.16 & 0.11 \\
\hline
\end{tabular}

Table 6: Regression of Effects of Credit Events on Corporate bonds, Treasuries and Stocks 


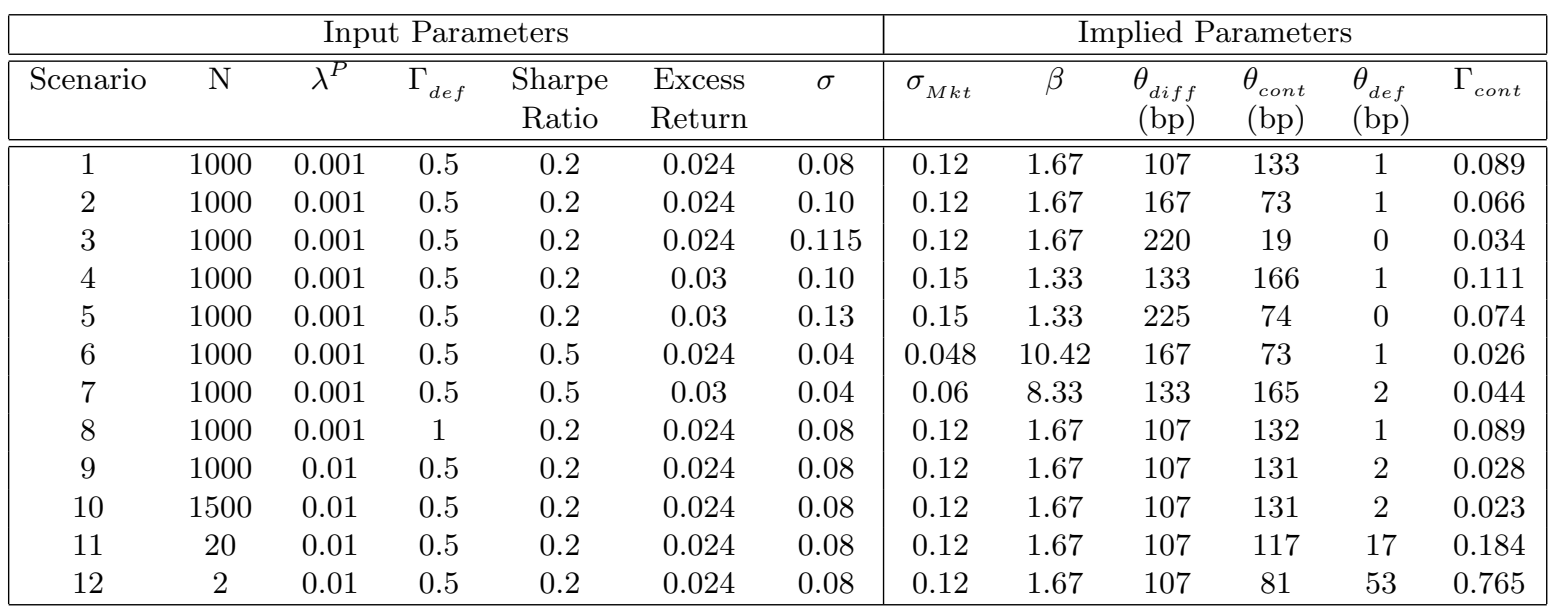

Table 7: Implied contagion risk premia for select inputs.

\begin{tabular}{|ccccccccc|}
\hline Scenario & $\mathrm{N}$ & $V_{\Lambda}$ & $\lambda^{p}$ & $\Gamma_{\xi, i}$ & $\Gamma_{k, i}$ & $\Gamma_{k}$ & $\begin{array}{c}\text { Jump to default } \\
\text { premium }(\mathrm{bp})\end{array}$ & $\begin{array}{c}\text { Contagion } \\
\text { premium (bp) }\end{array}$ \\
\hline 1 & 1000 & 0.25 & 0.001 & 0.50 & 0.0039 & 0.5 & 2.5 & 19.5 \\
2 & 1000 & 0.50 & 0.001 & 0.71 & 0.0039 & 0.5 & 3.5 & 27.6 \\
3 & 1000 & 0.25 & 0.001 & 0.50 & 0.0076 & 0.5 & 2.5 & 38.0 \\
4 & 1500 & 0.25 & 0.001 & 0.41 & 0.0039 & 0.5 & 2.5 & 23.9 \\
5 & 1000 & 0.25 & 0.001 & 0.50 & 0.0039 & 1.0 & 5.0 & 19.5 \\
6 & 100 & 0.25 & 0.001 & 1.58 & 0.0039 & 0.5 & 2.5 & 6.2 \\
7 & 1000 & 0.25 & 0.01 & 0.16 & 0.0039 & 0.5 & 25 & 61.7 \\
8 & 1000 & 0.50 & 0.01 & 0.22 & 0.0039 & 0.5 & 25 & 87.2 \\
9 & 1000 & 2.50 & 0.01 & 0.50 & 0.0039 & 0.5 & 25 & 195.0 \\
\hline
\end{tabular}

Table 8: Implied contagion risk premia for select inputs. 